\title{
Streptomyces-Derived Metabolites with Potential Photoprotective Properties-A Systematic Literature Review and Meta-Analysis on the Reported Chemodiversity
}

\author{
Jeysson Sánchez-Suárez ${ }^{1,2}\left(\mathbb{0}\right.$, Ericsson Coy-Barrera ${ }^{3}\left[\right.$, Luisa Villamil $^{1}$ and Luis Díaz ${ }^{1,2, *(1)}$ \\ 1 Doctoral Program of Biosciences, School of Engineering, Universidad de La Sabana, Chía 140013, \\ Cundinamarca, Colombia; jeyssonsasu@unisabana.edu.co (J.S.-S.); luisa.villamil@unisabana.edu.co (L.V.) \\ 2 Bioprospecting Research Group, School of Engineering, Universidad de La Sabana, Chía 140013, \\ Cundinamarca, Colombia \\ 3 Bioorganic Chemistry Laboratory, Universidad Militar Nueva Granada, Bogotá 110111, Cajicá, \\ Cundinamarca, Colombia; ericsson.coy@unimilitar.edu.co \\ * Correspondence: luis.diaz1@unisabana.edu.co
}

Academic Editors: Anna Andolfi and Maria Michela Salvatore

Received: 5 June 2020; Accepted: 7 July 2020; Published: 15 July 2020

\begin{abstract}
Sun overexposure is associated with the development of diseases that primarily affect the skin, which can lead to skin cancer. Among the main measures of photoprotection is the use of sunscreens. However, there is currently concern about the reported harmful effects to both humans and the environment due to several of the sunscreen ingredients available on the market. For this reason, the search for and development of new agents with photoprotective properties is required. In searching for these metabolites, researchers have turned their attention to microbial sources, especially the microbiota in unusual hostile environments. Among the diverse microorganisms available in nature, Actinobacteria and specifically Streptomyces, have been shown to be a source of metabolites with various biological activities of interest, such as antimicrobial, antitumor and immunomodulator activities. Herein, we present the results of a systematic review of the literature in which Streptomyces isolates were studied as a source of compounds with photoprotective properties. A meta-analysis of the structure-property and structure-activity relationships of those metabolites identified in the qualitative analysis phase was also carried out. These findings indicate that Streptomyces are a source of metabolites with potential applications in the development of new, safe and more eco-friendly sunscreens.
\end{abstract}

Keywords: actinobacteria; Streptomyces; antioxidant activity; UV-absorbing; anti-inflammatory; photoprotection; sunscreen

\section{Introduction}

Actinic damage or injury in humans refers to the negative effects of solar ultraviolet radiation (UVR) and it is well-documented in skin biology [1]. UVR is the main etiological factor of several skin conditions, such as photoaging, melasma and skin cancers [2]. The latter condition is currently of great concern due to the increase in the incidence rate [3]. On the other hand, photoprotection is defined as the set of chemical, physical and behavioral-based actions to prevent or counteract the actinic damage [1]. Likewise, among the different preventive photoprotection measures, the use of sunscreens is one of the main recommended actions to avoid the harmful effects of sun exposure, after clothing and behavior strategies [3]. 
A sunscreen works by mitigating the deleterious effects of UVR on skin. Therefore, sunscreens have compounds that can absorb, reflect or scatter UVR [4]. These agents are known as UV filters and are classified according to their chemical nature into inorganics and organics. The former consists of titanium dioxide $\left(\mathrm{TiO}_{2}\right)$ and zinc oxide $(\mathrm{ZnO})$ and the latter consists of different options depending on the regulatory norms in each country (e.g., in the FDA monograph there are 16 organic UV filters) $[5,6]$. Regardless of the type of UV filter, it has been shown that both can act mainly by absorbing UVR [7]. In the case of organic UV filters, the occurrence of conjugated double bonds is a crucial feature to being able to absorb UV light, which is then dissipated as heat [4]. However, sunscreening agents are currently associated with some adverse effects to a greater or lesser extent, either by affecting human health or by polluting natural ecosystems or both, in the worst cases [8-11].

Several side effects have been associated with some ingredients in sunscreens currently available in the market. For example, several studies have found that some of the most used UV-filters (e.g., benzophenone-3,3-benzylidene camphor, 3-(4-methyl-benzylidene) camphor, 2-ethylhexyl 4-methoxy cinnamate, homosalate, 2-ethylhexyl 4-dimethylaminobenzoate and 4-aminobenzoic acid, PABA) can act as endocrine-disrupting chemicals [12]. In addition, camphor and benzophenone derived UV-filters have shown to be detrimental agents against marine organisms [13]. There is some reported information stating that these compounds can be bioaccumulated in marine organisms that are part of the food chain [14] and some are associated with harmful effects on coral health [15,16].

Furthermore, although sunscreen production has focused on the use of compounds that affect the transmission of UVR to the skin (both inorganic and organic UV filters), it is known that a photoprotective effect could be achieved through the modification of the UVR physiological effects on the skin $[17,18]$. Particularly, among the claims made for current sun protection products, some state that these products must incorporate antioxidant and anti-inflammatory activities in addition to the UV-absorbing/filtering abilities [19-21]. This upgrade is pertinent, since the actinic damage involves both oxidative stress and inflammatory response in the skin [22]. In fact, bearing in mind that the generation of reactive oxygen species (ROS) and inflammation are early steps in cutaneous photocarcinogenesis [23], sunscreens might become skin cancer chemopreventive products by the incorporation of compounds that exhibit antioxidant and anti-inflammatory activities [24].

Considering the abovementioned facts, there is not an ideal sunscreen owing to the described limitations for the currently available sun protection products. Therefore, there is an undeniable need to find safer, eco-friendly and upgraded alternatives to serve as new ingredients for sunscreen improvement. In this regard, natural products constitute an essential opportunity to discover compounds with engaging biological activities for both pharmaceutical and cosmetic industries [25,26]. Despite such promising chemical and biological traits, research on compounds of natural origin has several significant logistical and technological disadvantages that limit their industrial application, such as the naturally occurring complex structures (expensive and time-consuming to synthesize) [27], low yield during the isolation process and limited availability of source organisms to yield higher amounts to satisfy supply $[28,29]$. However, the technological advances in biotechnology and analytics have identified improved approaches to overcome such challenges and produce compounds of industrial interest on a commercially large-scale based on natural molecules [30,31]. In this context, the success of microbial biotechnology for the industrial application of products derived from nature is well-known. For instance, several microorganism-derived products, such as antibiotics, enzymes, enzyme inhibitors, peptides and vaccines, are currently used in the pharmaceutical industry [32]. An advantage of the use of microorganisms as biofactories of biologically active compounds lies in their fast-growing attribute [32,33]. Another convenient feature is the possibility to produce the target compounds by fermentation, which is relatively easier than obtaining them from a macroorganism [32]. In addition to these facts, the diversity of microorganisms, compared to macroorganisms, is staggeringly higher. This diversity may be extended to the availability of a broad repertoire of different biosynthetic gene clusters [34-36], which can provide a varied and broad number of compounds with unique chemical structures $[37,38]$. 
Within the vast biodiversity of microorganisms available in nature, members of actinobacterial genus Streptomyces are one of the most prolific and successful groups of bacteria producers of bioactive compounds [39]. It is estimated that they are major producers of antibiotics used in human infection treatments [40,41]; approximately $70 \%$ of clinically used antibiotics come from actinomycetes, mainly Streptomyces [42]. Moreover, other activities, such as antitumor, immunomodulator and hypercholesteremic activities, have been reported for Streptomyces-derived metabolites, even the production of enzymes with therapeutic value [39]. In the specific instance of photoprotective activities, several actinobacterial species have also been shown to produce metabolites with antioxidant and UV-absorbing capabilities [43-46]. However, the potential of Streptomyces strains as a source of metabolites with the capability to be applied as photoprotective agents to be included into sunscreening products have been poorly explored.

Streptomyces have a unique genetic structure comprising complex regulatory networks. Such a structure involves different gene clusters, even silent/cryptic ones, encoding several metabolic pathways for the synthesis of functionally and structurally different secondary (also called specialized) metabolites [47]. Consequently, Streptomyces-related microorganisms can produce very interesting metabolites and several of them have bioactivities and applications of industrial interest. This chemical repertoire has conferred particular biological traits to Streptomyces to adapt to different environmental conditions [48]. Therefore, they can be found on air, soil, freshwater and seawater [39] and not only as free-living organisms but also as symbionts [49]. This ubiquity suggests the evolutionary success of their secondary metabolite arsenal and correlates with the relevance of their ecological functions [50,51]. Furthermore, given that the bioactivity profile of Streptomyces-derived metabolites is not yet fully described, we intended to explore what metabolites may be associated with a photoprotective role. With this in mind, we accomplished a systematic literature review of metabolites produced by Streptomyces spp. that have UV-absorbing, antioxidant and anti-inflammatory activitiesthese activities can contribute to achieve a photoprotective action by mitigating the deleterious effects of UVR [18]. Subsequently, from the group of compiled compounds during the systematic survey, we classified the compound library into several subclasses regarding the type of secondary metabolite. Additionally, we explored their potential as photoprotective agents through a meta-analysis of the structure-property (SPR) and structure-activity relationship analysis (SAR). This systematic review and meta-analysis aimed to identify, summarize and evaluate the evidence regarding the potential of Streptomyces strains as a biological source of metabolites with photoprotective-related properties.

\section{Results}

\subsection{General Findings}

The literature search identified 1789 potential studies. From this number, 694 articles were found to be duplicates and the remaining 1095 studies were screened by reading the titles and abstracts according to the inclusion/exclusion criteria. From this screening, 204 papers were selected for full-text assessment. Accordingly, 146 papers were finally included for data extraction. As most articles reported antioxidant capacity under the DPPH (2,2-diphenyl-1-picrylhydrazyl) radical scavenging assay, a meta-analysis approach was additionally feasible to compare results among them. In this regard, we identified 23 studies providing the half-maximal inhibitory concentration $\left(\mathrm{IC}_{50}\right.$, that is, concentration required for $50 \%$ reduction of the DPPH radical) as a result of DPPH assays. Furthermore, from the reported datasets of two articles, we were able to calculate the respective $\mathrm{IC}_{50}$ values. Thus, 25 articles were included in the meta-analysis. Figure 1 summarizes the full process.

Although the earliest report found in the review dates back 1987, the greatest number of articles (59.0\%) were published between 2014 and 2019 (Figure 2A). This increased number of publications was associated with the number of participating countries. Until 2008, publications were restricted to five countries; in the period 2009-2013, they increased to eight and during 2014-2019 they reached 18, resulting in a total of 23 countries (Figure 2). However, it should be noted that the publication number 
is still insignificant and regions such as Latin America, Africa and most of Europe are poorly explored territories in this research field (Figure 2B).

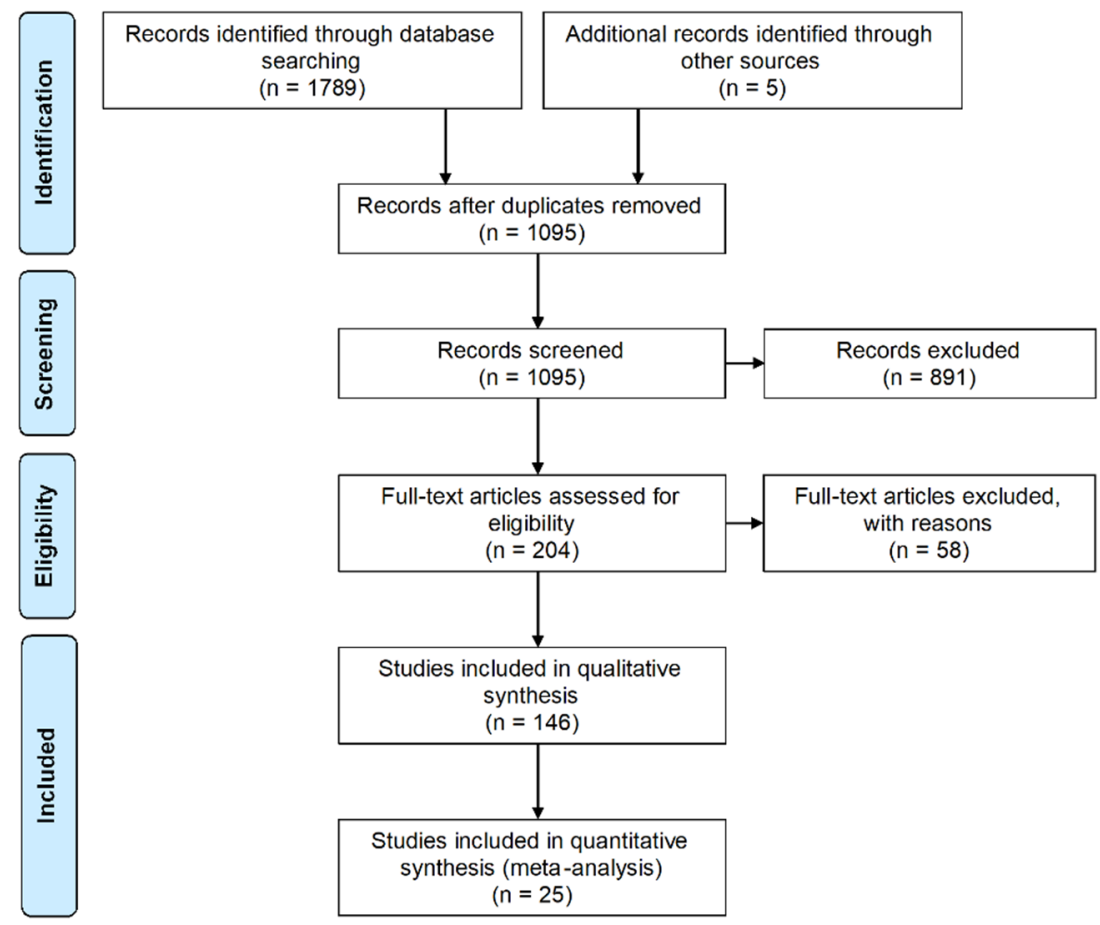

Figure 1. PRISMA flow diagram. Flowchart of systematic literature search according to PRISMA guidelines. Modified from: Moher D, Liberati A, Tetzlaff J, Altman DG, The PRISMA Group (2009). Preferred Reporting Items for Systematic Reviews and Meta-Analyses: The PRISMA Statement. PLoS Med 6 (7): e1000097 [52].

A

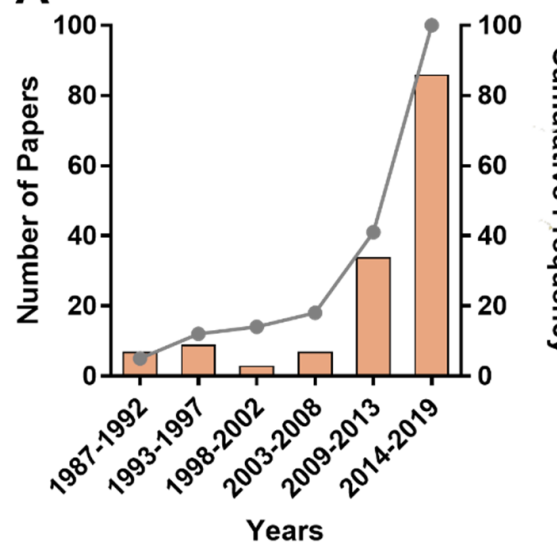

B

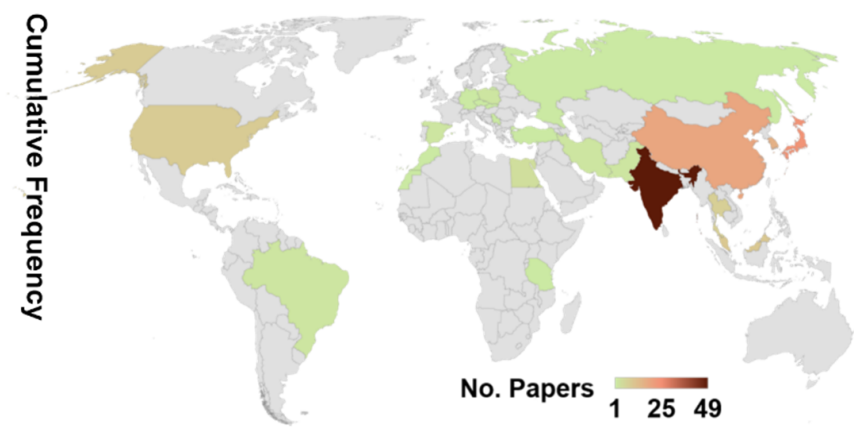

Figure 2. The number of papers in the literature by years and country of origin. (A) Publication distribution over the time. The first $y$-axis shows the number of papers and the second $y$-axis shows the cumulative frequency distribution. (B) World map showing the countries where the articles included in this review were produced, specifically, the corresponding author affiliation. Only in nine articles $(6.2 \%)$, the sampling place for isolating Streptomyces was different from the country of the corresponding author (See Figure S1).

Regarding biological activities, most of the articles (73.3\%) focused on antioxidant capacity (Figure 3A); 67.1\% evaluated only the antioxidant potential, whereas $6.2 \%$ involved measurement of the antioxidant capacity along with other bioactivities (i.e., anti-inflammatory or UV-absorbing). 
The anti-inflammatory potential was reported in $26.7 \%$ of the studies. The UV-absorbing ability was evaluated in only three papers, representing $2.1 \%$ of the selected publications. In relation to the type of substance, there was no marked difference between crude extracts and pure compounds. Crude extracts were used by $43.2 \%$ of the articles and pure compounds were used by the remaining $56.8 \%$ (Figure 3B). Considering that Streptomyces are ubiquitous in nature, either in terrestrial or marine environments $[53,54]$, we also examined the habitat source where the Streptomyces strain was isolated (Figure 3C). Although some papers (12.3\%) did not document the origin of the isolated strain, most strains (52.7\%) were isolated from terrestrial environments and $34.9 \%$ of strains were isolated from marine habitats. Finally, the role of symbiosis in the evolution of Streptomyces is a very important factor, particularly in their gene machinery for the biosynthesis of secondary metabolites [49]. For this reason, we considered whether the strains were isolated as free-living or symbiotic microorganisms (Figure 3D). We found that most studies focused on free-living Streptomyces (65.1\%) and very few studies used symbiotic strains $(22.6 \%)$.

A

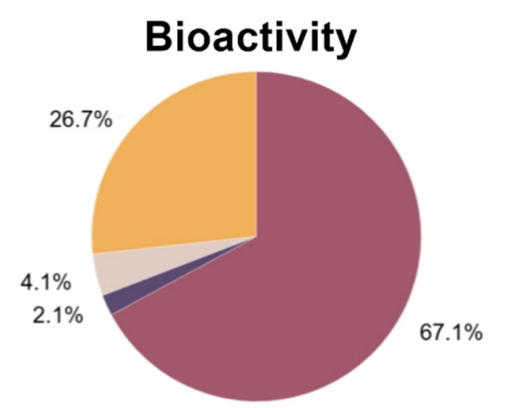

$\begin{array}{lrrr}\text { Antioxidant } & 98 & \text { Antioxidant/UV-absorbing } & 3 \\ \text { Antioxidant/Anti-inflammatory } & 6 & \text { Anti-inflammatory } & 39\end{array}$

C

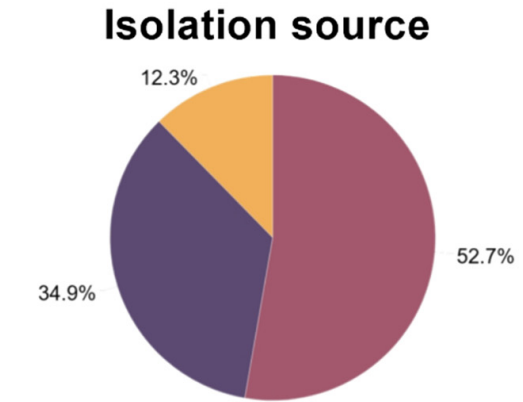

Terrestrial 77 OMarine $51 \quad$ NA $\quad 18$
B

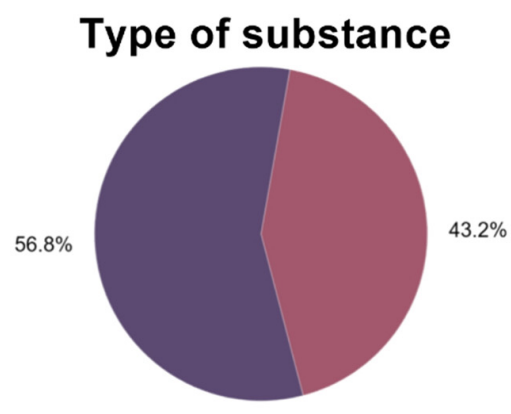

Crude Extract 63 Pure Compound 83

D Type of microorganism

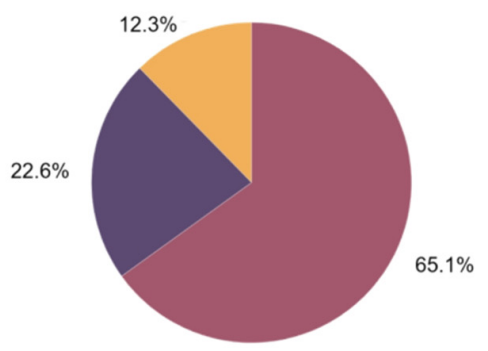

Free-living $95 \quad$ Symbiotic $33 \quad$ NA $\quad 18$

Figure 3. Characteristics of the information registered in the selected articles. The publications were grouped according to the information extracted for the analysis. (A) Percentage of articles by biological activity. (B) Percentage of articles that evaluated either crude extracts or pure compounds. (C) Percentage of articles by the environment where the isolation occurred (i.e., terrestrial, marine or not available). (D) Percentage of articles by the type of Streptomyces strain isolated (i.e., free-living, symbiotic or not available). At the bottom of each pie chart, the number of papers for each group is presented.

\subsection{Streptomyces as a Biological Source of Photoprotective Metabolites}

As mentioned above, photoprotection can be achieved by compounds participating as UV-absorber, antioxidant and anti-inflammatory agents [19-21]. Actually, a better photoprotective effect is reached by the combination of those compounds exhibiting these activities $[55,56]$. Hence, to evaluate the potentiality of Streptomyces as a source of photoprotective metabolites, we explored the literature 
records on Streptomyces strains with any of these activities (i.e., UV-absorbing, antioxidant and anti-inflammatory). The crude extract activity is a valuable measure of an organism's potential to produce metabolites with a particularly interesting function. In this case, 63 studies were found to evaluate the bioactivity of crude extracts obtained from Streptomyces strains. Table 1 summarizes the number of strains, isolation source and type of microorganism, along with the evaluated bioactivity.

Table 1. Number of Streptomyces strains with crude extract screened for photoprotective-related activities.

\begin{tabular}{llcc}
\hline \multirow{2}{*}{ Source } & \multicolumn{1}{c}{ Bioactivity } & $\begin{array}{c}\text { No. } \\
\text { Strains }\end{array}$ & Ref. \\
\hline \multirow{2}{*}{ Terrestrial (Free-living) } & Antioxidant & 24 & {$[57-76]$} \\
& Antioxidant/Anti-inflammatory & 2 & {$[77-79]$} \\
Terrestrial (Symbiont) & Antioxidant & 26 & {$[80-87]$} \\
& Antioxidant/Anti-inflammatory & 1 & {$[88]$} \\
Marine (Free-living) & Antioxidant & 29 & {$[89-113]$} \\
Marine (Symbiont) & Antioxidant/Anti-inflammatory & 2 & {$[114,115]$} \\
\multirow{2}{*}{ NA ${ }^{\text {a }}$} & Antioxidant & 2 & {$[116,117]$} \\
& Antioxidant & 2 & {$[118]$} \\
& Anti-inflammatory & 1 & {$[119]$} \\
& Total & $\mathbf{8 9}$ & $\mathbf{6 3}$ \\
\hline
\end{tabular}

${ }^{a}$ Information not available.

The antioxidant capacity was evaluated in 88 of the 89 extracts studied. As expected, $91.0 \%$ ( $\mathrm{n}=81$ ) of the publications reported DPPH as the selected method to determine the antioxidant potential, thus facilitating the comparison of the results among studies. The $\mathrm{IC}_{50}$ of the Streptomyces crude extracts were obtained and listed in Table 2 and converted to a logarithmic scale and presented in a dot blot (Figure 4). It was found that some crude extracts had radical scavenging capacity at a level similar to that of some reference antioxidant compounds that was independent of the source ecosystems (i.e., marine or terrestrial).

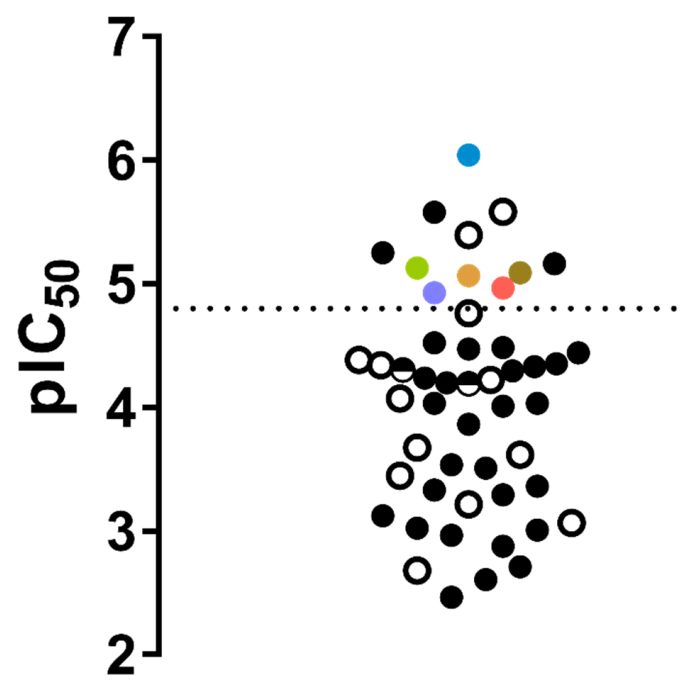

\section{Crude Extracts}

Figure 4. Distribution of antioxidant capacity of Streptomyces-derived crude extracts measured by the $\mathrm{DPPH}$ assay. The $\mathrm{IC}_{50}$ are presented as $-\log \mathrm{IC}_{50}\left(\mathrm{~g} \mathrm{~mL}^{-1}\right)$. The empty circles $(\bigcirc)$ represent crude extracts of marine origin and filled circles $(\bullet)$ represent crude extracts of terrestrial origin. The colored circles show reference antioxidant compounds (i.e., ascorbic acid $\bullet$, butylhydroxytoluene $\bullet$, $\alpha$-tocopherol $\bullet$, rutin $\bullet$, novobiocin $\bullet$, quercetin $\bullet$ ). Dotted line indicates the minimum limit potency of reference antioxidant compounds. 
Table 2. Antioxidant capacity of crude extracts from Streptomyces strains.

\begin{tabular}{|c|c|c|c|}
\hline Strain Name & $\mathrm{IC}_{50} \mu \mathrm{g} \mathrm{mL}^{-1}$ & $\mathrm{pIC}_{50}{ }^{\mathrm{a}}$ & Ref. \\
\hline Streptomyces sp. KB3 & 64.24 & 4.192 & \multirow{2}{*}{ [118] } \\
\hline Streptomyces sp. KB1 & 49.65 & 4.304 & \\
\hline Streptomyces sp. LK3 & 41.09 & 4.386 & [96] \\
\hline Streptomyces sp. Loyola AR1 & 750.50 & 3.125 & [62] \\
\hline Streptomyces sp. Loyola UGC & 435.31 & 3.361 & [85] \\
\hline Streptomyces sp. MJM 8637 & 977.20 & 3.010 & [79] \\
\hline Streptomyces sp. MJM 10778 & 92.80 & 4.032 & [63] \\
\hline Streptomyces sp. OS-6 & 2.63 & 5.580 & \multirow{2}{*}[64]{} \\
\hline Streptomyces sp. TES-25 & 46.61 & 4.332 & \\
\hline Streptomyces sp. PS4 & 950.00 & 3.022 & [65] \\
\hline Streptomyces sp. SC 156 & 211.20 & 3.675 & [117] \\
\hline Streptomyces sp. SMS_7 & 609.00 & 3.215 & \multirow{3}{*}{ [103] } \\
\hline Streptomyces sp. SMS_SU13 & 356.00 & 3.449 & \\
\hline Streptomyces sp. SMS_SU21 & 242.00 & 3.616 & \\
\hline Streptomyces sp. UTMC 1334 & 45.67 & 4.340 & [104] \\
\hline Streptomyces sp. VITMSS05 & 92.49 & 4.034 & [67] \\
\hline Streptomyces sp. IB 2014 I 73-1 & 50.67 & 4.295 & \multirow{12}{*}{ [84] } \\
\hline Streptomyces sp. IB 2014 I 73-1HS & 33.79 & 4.471 & \\
\hline Streptomyces sp. IB 2014 I 73-2HS & 63.39 & 4.198 & \\
\hline Streptomyces sp. IB 2014 I 74-1 & 57.65 & 4.239 & \\
\hline Streptomyces sp. IB 2014 I 74-2HS & 44.22 & 4.354 & \\
\hline Streptomyces sp. IB 2014 I 74-3 & 32.87 & 4.483 & \\
\hline Streptomyces sp. IB 2014 I 74-4 HS & 292.11 & 3.534 & \\
\hline Streptomyces sp. IB 2014 I 74-7HS & 6.89 & 5.162 & \\
\hline Streptomyces sp. IB 2014 I 75-1HS & 136.86 & 3.864 & \\
\hline Streptomyces sp. IB 2014 I 75-2HS & 36.12 & 4.442 & \\
\hline Streptomyces sp. IB 2014 I 75-4HS & 1940.70 & 2.712 & \\
\hline Streptomyces sp. IB 2014 I 77-1 & 310.05 & 3.509 & \\
\hline Streptomyces sp. A071 & 466.17 & 3.331 & \multirow{4}{*}{ [81] } \\
\hline S. globosus A012 & 97.60 & 4.011 & \\
\hline S. hypolithicus A100 & 1080.00 & 2.967 & \\
\hline S. phaeochromogenes A009 & 1325.00 & 2.878 & \\
\hline S. carpaticus MK-01 & 84.50 & 4.073 & [101] \\
\hline S. cellulosae TES17 & 2480.00 & 2.606 & [69] \\
\hline S. coelicoflavus BC 01 & $2.61^{\mathrm{b}}$ & 5.583 & \multirow{3}{*}{ [107] } \\
\hline S. coelicoflavus BC 02 & $4.02^{b}$ & 5.396 & \\
\hline S. coelicoflavus BC 04 & $17.28^{\mathrm{b}}$ & 4.762 & \\
\hline S. flavoviridis A3WK & 3430.00 & 2.465 & [88] \\
\hline S. griesoruber S2A & 860.00 & 3.066 & [108] \\
\hline S. hydrogenans NAF-1 & 5.58 & 5.253 & [82] \\
\hline S. lavendulae SCA5 & 507.61 & 3.294 & [74] \\
\hline S. nogalater NIIST A30 & 30.00 & 4.523 & [76] \\
\hline S. omiyaensis SCH2 & 2078.13 & 2.682 & [113] \\
\hline S. variabilis DV-35 & 60.00 & 4.222 & [94] \\
\hline
\end{tabular}

${ }^{\mathrm{a}}$ Calculated as $-\log \mathrm{IC}_{50}\left(\mathrm{~g} \mathrm{~mL}^{-1}\right) .{ }^{\mathrm{b}}$ Calculated from the data shown in the article. 
On the other hand, the biological activity evaluation of pure compounds could lead to more accurate analysis because the plausible mechanisms of action and structure-activity/property relationship analysis could be proposed. Both have a priceless value for the development of products in the pharmaceutical industry [120]. In this sense, 75 Streptomyces strains were identified and from these, 133 biologically active purified compounds were reported (Table 3; see Table S2 for detailed data). Interestingly, it was found that some Streptomyces strains produce more than one bioactive compound. Unlike crude extracts, we could find compounds where the UV-absorbing activity was evaluated and the number of anti-inflammatory activity reports was significantly higher (i.e., 66 anti-inflammatory compounds—see Table 3-versus six anti-inflammatory extracts—see Table 1).

Table 3. Number of Streptomyces strains and pure compounds screened for photoprotective-related activities.

\begin{tabular}{llccc}
\hline \multicolumn{1}{c}{ Source } & \multicolumn{1}{c}{ Bioactivity } & No. Strains & No. Compounds & Ref. \\
\hline \multirow{3}{*}{ Terrestrial (Free-living) } & Antioxidant & 19 & 35 & {$[121-141]$} \\
& Antioxidant/UV-absorbing & 2 & 2 & {$[142,143]$} \\
& Anti-inflammatory & 8 & 9 & {$[144-154]$} \\
Terrestrial (Symbiotic) & Antioxidant & 7 & 10 & {$[155-161]$} \\
& Anti-inflammatory & 5 & 11 & {$[162-168]$} \\
& Antioxidant & 2 & 2 & {$[169,170]$} \\
Marine (Free-living) & Antioxidant/UV-absorbing & 1 & 1 & {$[171]$} \\
& Antioxidant/Anti-inflammatory & 2 & 4 & {$[172,173]$} \\
Marine (Symbiotic) & Anti-inflammatory & 9 & 24 & {$[174-182]$} \\
\multirow{2}{*}{ NA ${ }^{\text {a }}$} & Antioxidant & 3 & 3 & {$[183-185]$} \\
Total & Anti-inflammatory & 5 & 11 & {$[186-190]$} \\
& Antioxidant & 8 & 14 & {$[191-197]$} \\
& Anti-inflammatory & 4 & 7 & {$[198-202]$} \\
\hline
\end{tabular}

${ }^{\text {a }}$ Data not available.

\subsection{Chemical Space Analysis}

To explore the 'biologically relevant chemical space' - in terms of photoprotective compounds reported so far, the metabolites registered in those articles included in the qualitative analysis phase were extracted to build a custom-made compound library. For this, their chemical structures were sketched and converted into SMILES notation and from this format, the chemical space analysis was performed using the software Osiris DataWarrior v5.2.1 (Idorsia Pharmaceuticals Ltd., Switzerland) [203]. In the Table S2, the identification number given for each compound is presented along with its respective SMILES notation.

As stated in the Section 1, our primary goal is to explore the evidence about the potential of Streptomyces as a producer of photoprotective metabolites. In this sense, we aimed to characterize the biological profile and chemical diversity of the Streptomyces-derived metabolites (herein identified and compiled) through a chemoinformatics-based analysis. Such an analysis was accomplished using the software DataWarrior involving three steps-(i) selection of the descriptor for the compound clustering, (ii) similarity analysis of the compounds, which is a useful approach to filter compounds and (iii) Structure-Property Relationships (SPR) and Structure-Activity Relationships (SAR) analyses of the custom-made compound library, whereby the correlation between chemical structures and bioactivity is established.

DataWarrior calculates similarity among molecules using descriptors that are obtained from particular structural features of test compounds [203]. To define the best descriptor to be used for the subsequent analysis, we evaluated the performance of some descriptors in the similarity analysis of the compound library. Hence, we evaluated the following three descriptors-(a) FragFp (a substructure fragment dictionary based binary fingerprint) [203], (b) PathFp (encodes all distinct linear strands of up to seven atoms within a molecule) [203] and (c) OrgFunctions (perceives molecules 
from a synthetic chemistry's point of view, that is, it classifies organic functional groups focusing on steric and electronic features) [203]. Accordingly, the SMILES-based format of compounds was first incorporated as a datasheet into DataWarrior. A similarity analysis (with default settings) using each descriptor (i.e., FragFp, PathFp and OrgFunctions) was then executed as shown in Figure 5. We found that OrgFunctions was the descriptor that arranged the compound set by higher similarity values. Thus, the proportions of compounds with similarity higher than 0.9 were $65 \%, 73 \%$ and $83 \%$, with FragFp, PathFp and OrgFunctions, respectively (see Figure 5D). In consequence, the similarity analysis of the metabolites was done using the OrgFunctions descriptor and the analysis with all the compounds saved in our library (133) was carried out as shown in Figure 5C.

A

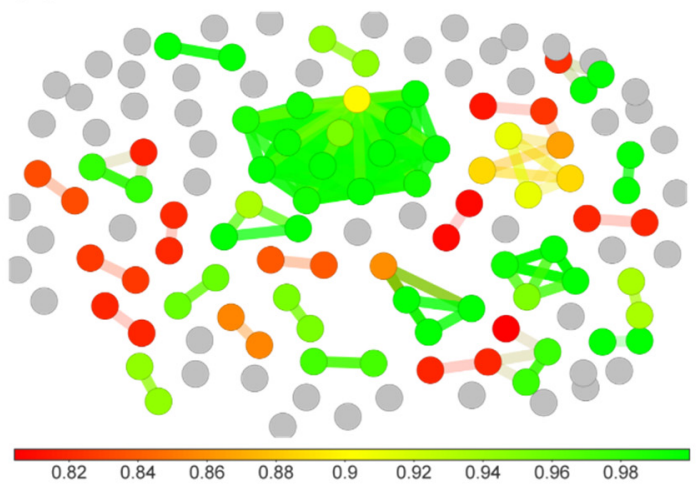

C

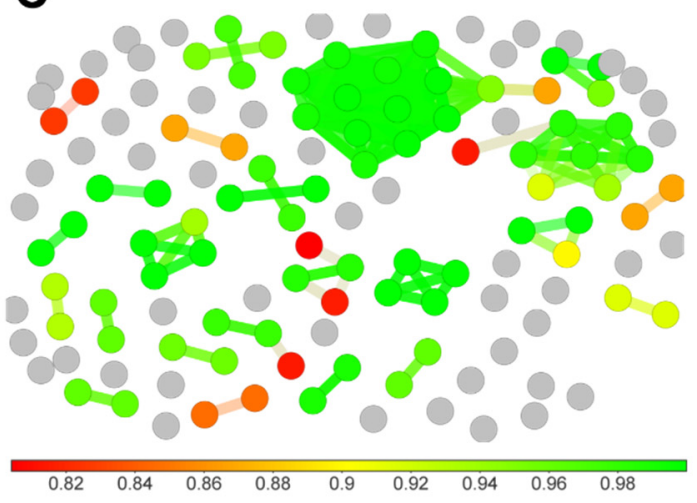

B

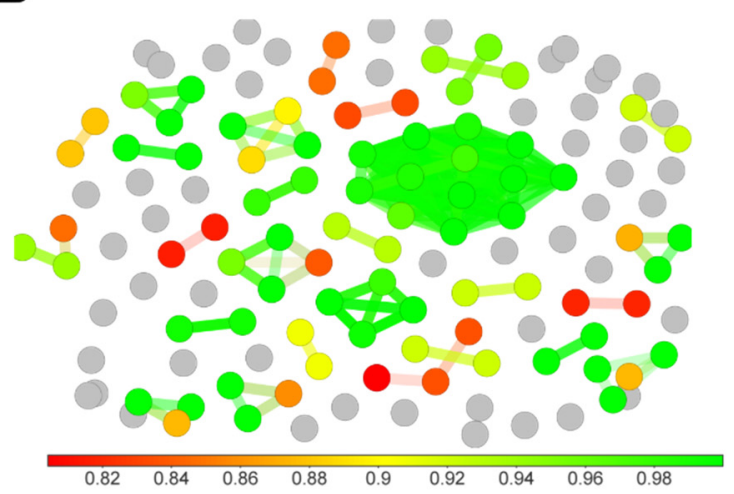

D

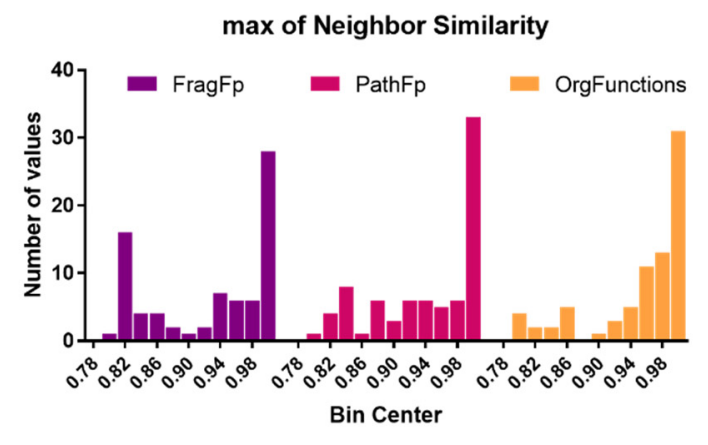

Figure 5. Similarity analysis of the chemical space using different descriptors. The level of similarity is indicated by a color scale bar (located at the bottom of each dot plot), from red (similarity $=0.8$ ) to green (similarity $=1.0$ ). Similarity analysis of the compound library was performed using (A) FragFp descriptor, (B) PathFp descriptor and (C) OrgFunctions descriptor. (D) Distribution frequency of each similarity value calculated by each descriptor.

A similarity analysis allows us to organize and measure the level of chemical diversity within the chemical space defined by the characteristics of the compound group [204]. In this particular aspect, such a measure of chemical diversity may be used as an indicator of biosynthetic aspects, for example, the heterogeneity of the biosynthetic pathways employed by a biological organism or group of them (e.g., organisms of the same species or genus) to produce a given group of compounds [204,205].

The level of chemical diversity and possible grouping of the compounds based on the biological activity was assessed. As shown in Figure 6, several unique fingerprints were observed, supporting a great diversity in the custom-made library. In addition, several clusters were identified that included different numbers of compounds. Particularly, some compounds ( $40 \%)$ were not able to be clustered, since the descriptor used did not find shared structural characteristics at a comparatively significant level. Thus, the analysis of anti-inflammatory and antioxidant compounds was carried out separately. 
It is important to point out that since the compounds 60, 64, 65 and 66 exhibited both bioactivities, they were included in the analysis of each group. The groups were defined as (a) anti-inflammatory metabolites, with 66 compounds and (b) antioxidant metabolites, with 71 compounds.

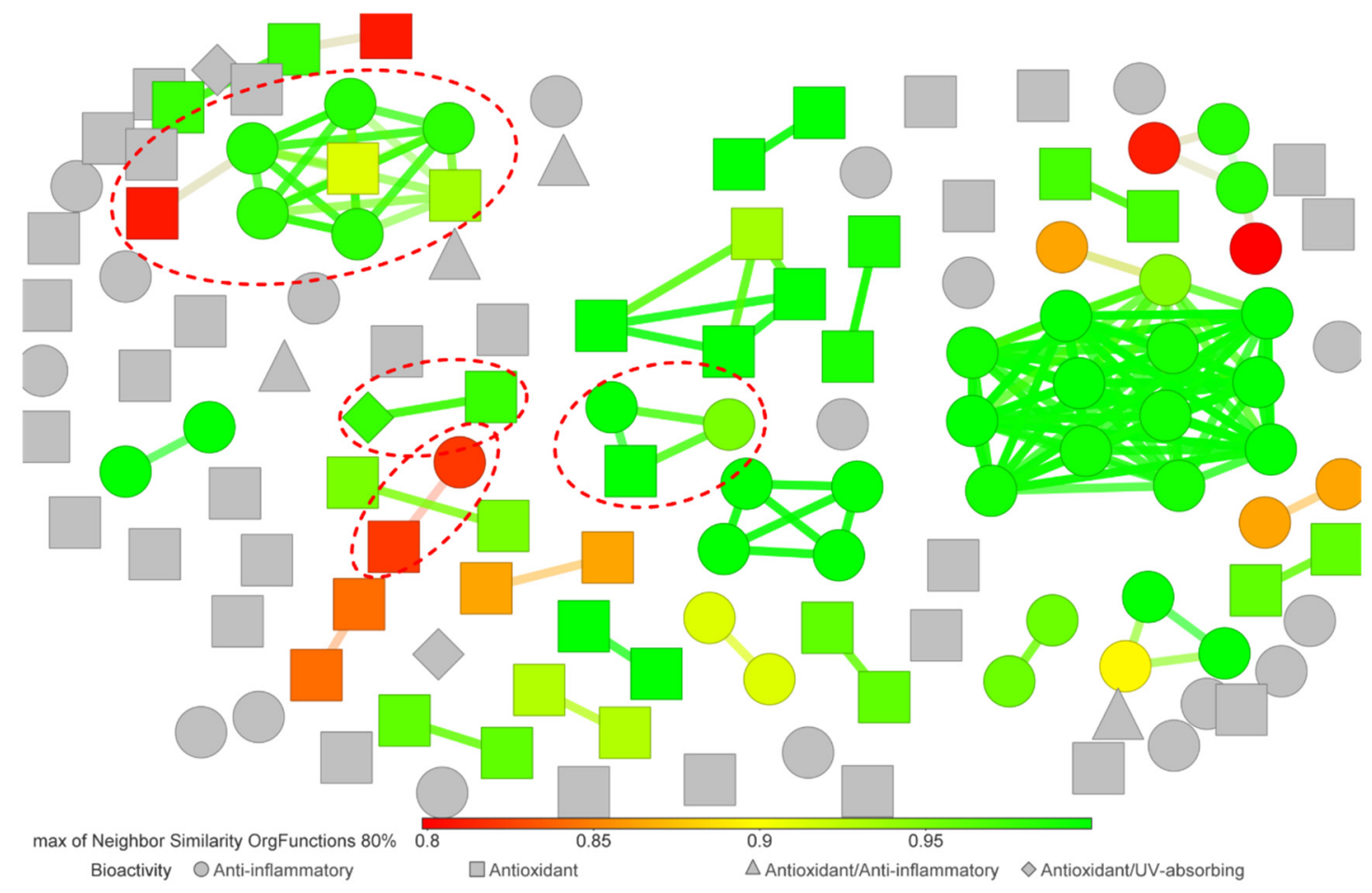

Figure 6. Similarity analysis of Streptomyces-derived photoprotective compound library. The similarity analysis was carried out using the OrgFunctions descriptor. The color scale bar indicates the level of similarity from red (0.8) to green (1.0). Each marker shape indicates the bioactivity reported for a given compound. The red dotted circles highlight compound clusters where metabolites with different bioactivity were grouped together.

Fewer unique fingerprints were found in the anti-inflammatory compounds' subgroup (35) in comparison to the antioxidant subgroup (55) (Figure 7A,B). In both subgroups, there was a wide range in molecular weight. As expected, clustering of structurally related compounds also grouped compounds with quite similar size, since other atomic arrangements not only affect the molecular weight but also the similarity, resulting in lower values. These facts could be related with the high diversity of biosynthetic pathways employed by Streptomyces to produce these compounds. To evaluate this possibility, the next task was to cluster the compounds of the evaluated subgroups according to their biosynthesis pathway (i.e., alkaloids, amides, phenylprenoids, polyketides, flavonoids and terpenoids).

Each metabolite in the compound library was classified as alkaloids, amides, phenylpropanoids, polyketides, flavonoids and terpenoids based on the elemental units identified in the molecular structure. Since compounds 52 and 53 showed mixed elemental units between phenylpropanoid and polyketide, it was necessary to incorporate a mixed phenylpropanoid/polyketide group. As shown in Figure 8, our compound library was mainly represented by alkaloids (33.1\%) and amides (24.8\%). Despite several of these compounds exhibiting mixed building blocks, they were classified into those classes due to the diversification/evolutionary concept that nitrogen-containing metabolites can imply specialized metabolism [206]. Interestingly, a singular trend was observed within the custom-made dataset, since the anti-inflammatory subgroup was mainly composed by amides, while the antioxidant subgroup was mainly represented by alkaloids. In general, it is important to clarify that Streptomyces has different biosynthetic pathways to produce metabolites with these biological activities. 

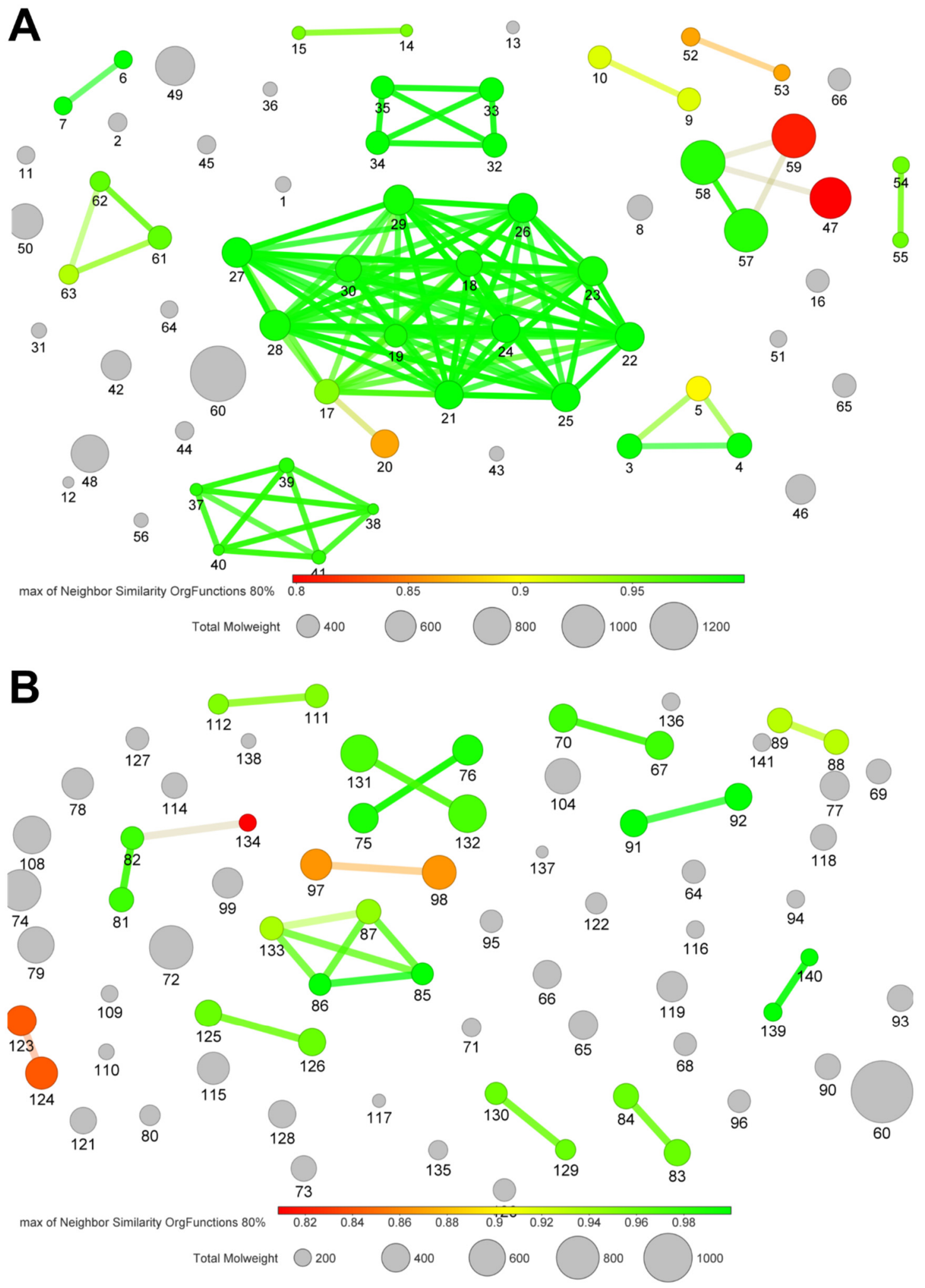

Figure 7. Similarity analysis of anti-inflammatory and antioxidant Streptomyces-derived metabolites. The similarity analysis was performed using the OrgFunctions descriptor. The color scale bar indicates the level of similarity from red (0.8) to green (1.0). Each marker size indicates molecular weight $\left(\mathrm{g} \mathrm{mol}^{-1}\right)$. (A) Compounds with anti-inflammatory activity. (B) Compounds with antioxidant capacity. 


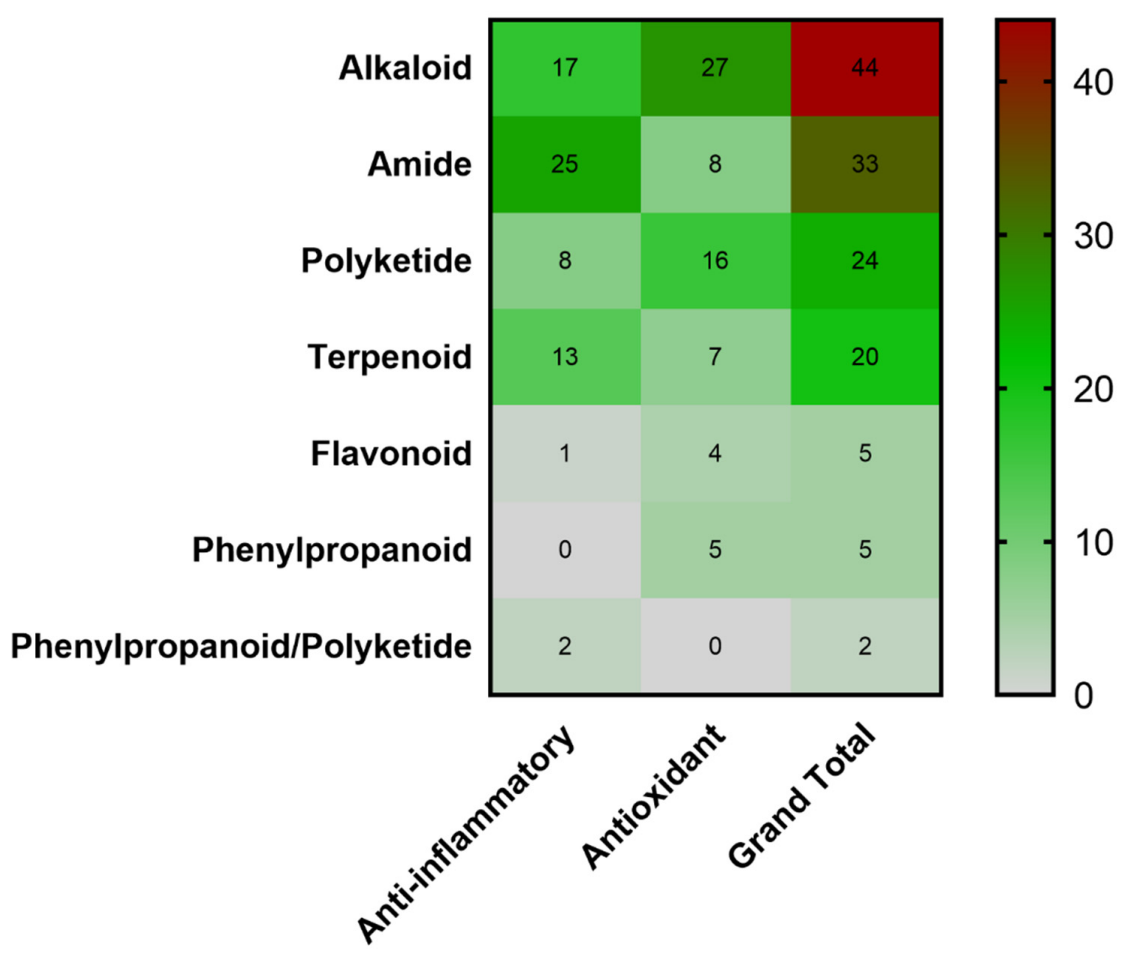

Figure 8. Heatmap analysis of Streptomyces-derived compound library. The compounds were classified as alkaloids, amides, polyketides, terpenoids, flavonoids, phenylpropanoids and mixed phenylpropanoid/polyketide according to the biosynthetically based chemical structure. Inside each cell, the number of compounds in the given group is presented. The color bar represents the number of compounds, gray (minor values), green (middle values) and red (high values).

Further analyses were also performed to establish molecular characteristics that may be associated with a specific biological activity. Particularly, a structure-property analysis (SPR) and structure-activity analysis (SAR) was performed with each subgroup of compounds, anti-inflammatory and antioxidant, respectively.

\subsection{SPR and SAR Analysis}

Owing to the anti-inflammatory activity was evaluated using different approaches, there was not a method used with a significant frequency to be selected. For instance, edema inhibition was reported in six papers. However, the results were not strictly comparable, since some evaluations were done on mice while the others involved rats as a model. Furthermore, some edema evaluations were induced in paw and others in the ears. Other remarkable facts were the variety in the methods to quantify inflammatory mediators-for example, ELISA, qPCR, Flow cytometry, Luminex 100 system. Even the target analyte varied mostly through the articles-for example, iNOS, COX-1, COX-2, TNF- $\alpha$, IL-1 $\beta,-2,-4,-5,-10,-13$. Therefore, the differences in the anti-inflammatory activity potency among metabolites could not be evaluated. Conversely, an SPR analysis was carried out in this case to visualize plausible relationships between structure and physicochemical characteristics. In contrast, most of the antioxidant capacity was evaluated using the DPPH radical scavenging assay, allowing the SAR analysis for these compounds.

Several Food and Drug Administration (FDA)-approved UV filters have shown anti-inflammatory activity [207]; it is even discussed that this anti-inflammatory activity promotes the photoprotective action of these UV filters [208]. In the case of SPR analysis, we included the UV filters with anti-inflammatory activity reported by Couteau et al. [207] as reference standards. The chemical structure was translated into SMILES annotation and analyzed using DataWarrior (i.e., 4-methylbenzylidene camphor, Benzophenone-3, Benzophenone-5, Bis-Ethylhexyloxyphenol methoxyphenyl triazine, Butylmethoxydibenzoylmethane, 
Diethylamino hydroxybenzoyl hexyl benzoate, Diethylhexylbutamidotriazone, Disodium phenyl dibenzimidazole tetrasulfonate, Ethyl hexyl methoxycinnamate, Ethylhexylsalicylate, Homosalate, Isoamyl p-methoxycinnamate, Methylene bis-benzotriazolyl tetramethylbutylphenol, Octocrylene, Octyl triazone, Octyldimethyl PABA, PEG-25 PABA and Phenylbenzimidazole sulfonic acid).

Considering that physicochemical properties, such as partition coefficient, solubility and molar mass are important properties of active agents affecting skin penetration [209], we calculated parameters associated with these properties (i.e., molecular weight, topological polar surface area (TPSA), octanol/water partition coefficient (cLogP), aqueous solubility (cLogS)), along with $H$-acceptors, $H$-donors and drug likeness, which are valuable criteria in pharmaceutical agents' discovery $[210,211]$. Additionally, we calculated the irritant risk, which is a common side effect in sunscreen ingredients [212]. Figure 9 shows that irritant risk (Figure 9B) and druglikeness values (Figure 9C) were the properties with the most substantial differences. To better understand druglikeness differences, a dot plot was generated including UV filters versus Streptomyces-derived anti-inflammatory metabolites. It was found that most UV filters $(83.3 \%)$ exhibited a druglikeness among -6 y 1 , as well as many anti-inflammatory compounds (50.8\%), as shown in Figure 9D. Regarding the risk of a compound to be an irritant, it was found that most UV filters (72\%) were classified as high risk, as previously reported [212], in opposition with Streptomyces-derived anti-inflammatory compounds, in which only $10 \%$ had a high risk of being irritant (Figure 9B). This result gives an idea of the possibility of finding safer compounds in Streptomyces-derived metabolites for the development of better sunscreens.

A

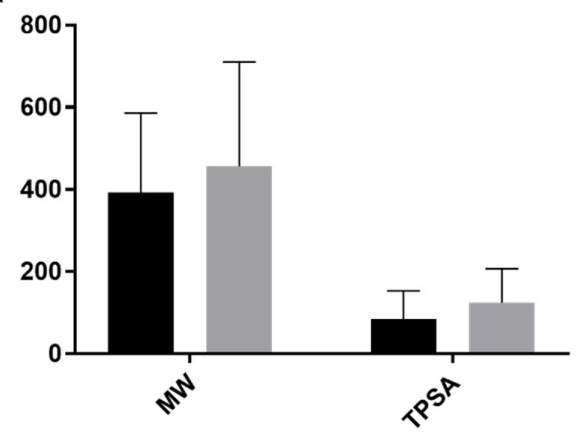

C

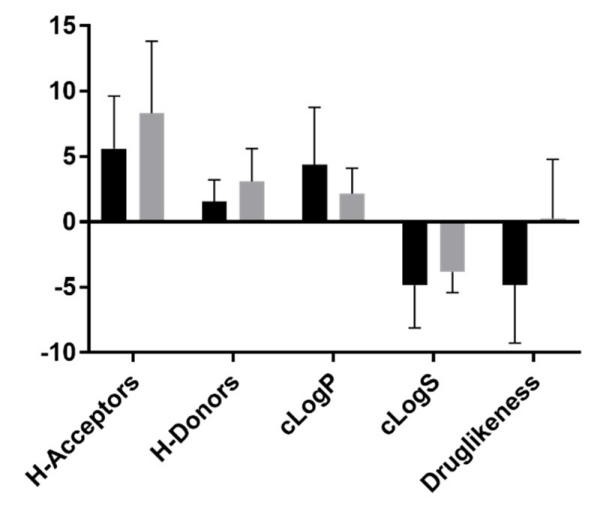

UV Filters
B

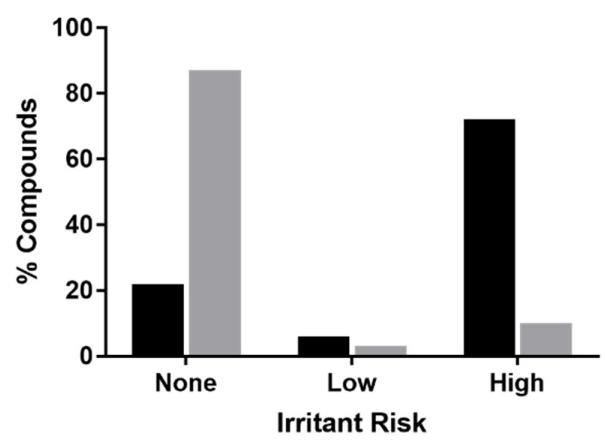

D

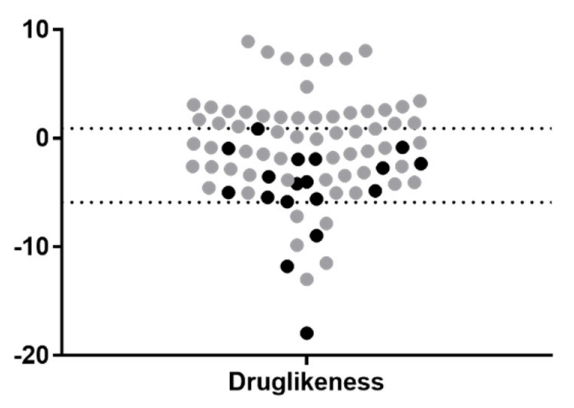

Streptomyces

Figure 9. Structure-Property Relationships (SPR) analysis of Streptomyces-derived anti-inflammatory compounds. Several physicochemical properties of the anti-inflammatory metabolites were calculated theoretically by DataWarrior. Data in black represent values of UV filters and data in gray represent values of Streptomyces-derived metabolites. (A) Molecular weight (MW) and topological polar surface area (TPSA). (B) Irritant risk indicator, calculated as none, low and high risk. (C) H-Acceptors, $H$-Donors, cLogP, cLogS and druglikeness. (D) Dot plot of druglikeness values. 
Regarding the antioxidant subgroup $(\mathrm{n}=71)$, 39 compounds where evaluated using the DPPH assay; 30 compounds reported the $\mathrm{IC}_{50}$ and it was also possible to calculate the $\mathrm{IC}_{50}$ of 4 other compounds using the data available in the publications (Table 4, compounds 64, 65, 66 and 69). Additionally, 11 compounds that, although evaluated by the DPPH radical scavenging assay, were not active or did not achieve more than $50 \%$ inhibition at the highest concentration evaluated were also incorporated (i.e., 61, 62, 63, 100, 101, 102, 103, 105, 106, 107 and 113). This information was included with the aim to promote a more robust analysis and allow the identification of activity cliffs (pairs of structurally similar compounds that have a large potency difference [213]). In total, including active and non-active agents, 45 compounds were involved in the SAR analysis.

Once establishing the compounds that satisfied the requirements for the SAR analysis, the $\mathrm{IC}_{50} \mathrm{~S}$ data were standardized, first in molarity units $(\mathrm{M})$ and then expressed logarithmically as $-\log \mathrm{IC}_{50}(\mathrm{M})$ (Table 4). Figure 10 presents the $\mathrm{IC}_{50}$ values of the Streptomyces-derived metabolites along with antioxidant reference compounds such as vitamin C (VC), butylated hydroxytoluene (BHT), vitamin E (as $\alpha$-tocopherol, $\mathrm{VE}_{\mathrm{AT}}$ ), novobiocin (NB) and quercetin (QUE), in order to illustrate the potency of the antioxidant capacity of the Streptomyces-derived compounds.

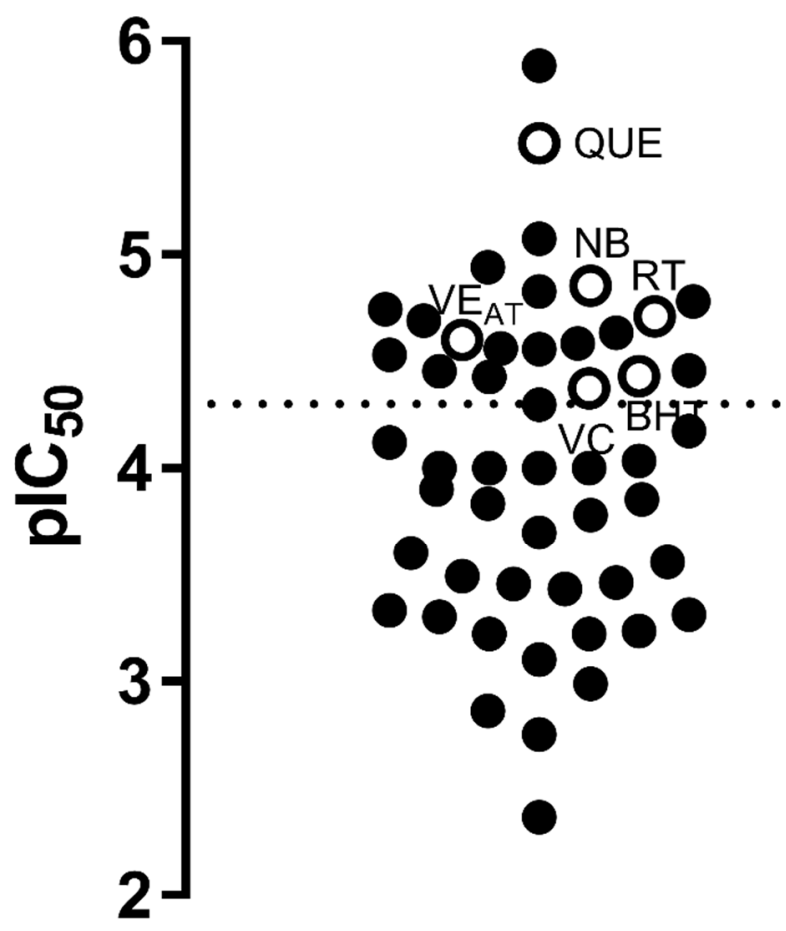

\section{Metabolites}

Figure 10. Distribution of Streptomyces-derived metabolites with DPPH radical scavenging capacity. The $\mathrm{pIC}_{50}$ of each compound was plotted along with some reference antioxidant compounds. Each black dot indicates a Streptomyces-derived metabolite and each empty dot indicates a reference antioxidant compound. VC, vitamin $\mathrm{C}$; BHT, butylated hydroxytoluene; $\mathrm{VE}_{\mathrm{AT}}$, vitamin $\mathrm{E}$ ( $\alpha$ - tocopherol); NB, novobiocin; and QUE, quercetin. Dotted line indicates the minimum limit potency of reference antioxidant compounds. 
Table 4. Antioxidant capacity of Streptomyces-derived metabolites.

\begin{tabular}{|c|c|c|c|c|}
\hline Compound Number & Molecular Weight $\left(\mathrm{g} \mathrm{mol}^{-1}\right)$ & $\mathrm{IC}_{50}(\mu \mathrm{M})$ & $\mathrm{pIC}_{50}{ }^{\mathrm{a}}$ & Ref. \\
\hline 61 & 411.342 & 486.21 & 3.3132 & [202] \\
\hline 62 & 343.223 & 582.71 & 3.2345 & [202] \\
\hline 63 & 332.446 & 601.60 & 3.2207 & [202] \\
\hline 64 & 295.421 & $67.06^{\mathrm{b}}$ & 4.1736 & [173] \\
\hline 65 & 411.581 & $29.33^{b}$ & 4.5327 & [173] \\
\hline 66 & 392.578 & $27.41^{\mathrm{b}}$ & 4.5621 & [173] \\
\hline 68 & 282.422 & 1770.40 & 2.7519 & [171] \\
\hline 69 & 323.439 & $25.96^{b}$ & 4.5858 & [143] \\
\hline 100 & 322.315 & 465.38 & 3.3322 & [214] \\
\hline 101 & 182.174 & 1372.31 & 2.8625 & [161] \\
\hline 102 & 243.265 & 1027.69 & 2.9881 & [161] \\
\hline 103 & 574.668 & 100.00 & 4.0000 & [138] \\
\hline 104 & 576.684 & 1.30 & 5.8861 & [138] \\
\hline 105 & 636.783 & 100.00 & 4.0000 & [139] \\
\hline 106 & 622.800 & 100.00 & 4.0000 & [139] \\
\hline 107 & 596.762 & 100.00 & 4.0000 & [139] \\
\hline 108 & 638.799 & 16.50 & 4.7825 & [139] \\
\hline 113 & 324.379 & 250.00 & 3.6021 & [123] \\
\hline 114 & 340.378 & 37.20 & 4.4295 & [123] \\
\hline 115 & 486.519 & 27.70 & 4.5575 & [123] \\
\hline 117 & 150.176 & 146.49 & 3.8342 & [170] \\
\hline 118 & 346.421 & 4329.99 & 2.3635 & [124] \\
\hline 119 & 444.391 & 165.00 & 3.7825 & [125] \\
\hline 120 & 280.381 & 8.40 & 5.0757 & [126] \\
\hline 121 & 354.576 & 14.90 & 4.8268 & [126] \\
\hline 122 & 260.337 & 34.70 & 4.4597 & [126] \\
\hline 123 & 444.526 & 11.40 & 4.9431 & [127] \\
\hline 124 & 483.607 & 35.10 & 4.4547 & [127] \\
\hline 125 & 360.361 & 370.00 & 3.4318 & [128] \\
\hline 126 & 374.388 & 18.00 & 4.7447 & [128] \\
\hline 127 & 284.270 & 125.00 & 3.9031 & [197] \\
\hline 128 & 378.335 & 792.95 & 3.1008 & [185] \\
\hline 129 & 244.245 & 351.45 & 3.4541 & [157] \\
\hline 130 & 274.271 & 321.80 & 3.4924 & [157] \\
\hline 131 & 622.924 & 139.28 & 3.8561 & [158] \\
\hline 132 & 638.923 & 92.22 & 4.0352 & [158] \\
\hline 133 & 298.293 & 600.00 & 3.2218 & [159] \\
\hline 134 & 198.177 & 346.16 & 3.4607 & [160] \\
\hline 135 & 226.183 & 20.38 & 4.6908 & [161] \\
\hline 136 & 206.196 & 277.02 & 3.5575 & [161] \\
\hline 137 & 138.122 & 200.00 & 3.6990 & [129] \\
\hline 138 & 168.191 & 500.00 & 3.3010 & [131] \\
\hline 139 & 212.204 & 50.30 & 4.2984 & [132] \\
\hline 140 & 198.177 & 75.80 & 4.1203 & [132] \\
\hline 141 & 207.184 & 23.26 & 4.6334 & [134] \\
\hline
\end{tabular}

There was a wide diversity in the potency of the free-radical scavenging capacity, since the $\mathrm{IC}_{50} \mathrm{~s}$ varied from 1.3 (104) to $4330 \mu \mathrm{M}$ (118). To evaluate the implications of the chemical structure in the heterogeneity of the antioxidant potency, a similarity analysis was conducted (using the OrgFunctions descriptor in the same way as with the group of anti-inflammatory compounds). The similarity analysis indicated the existence of nine clusters and with these in hand, a Structure-Activity Landscape Index (SALI) analysis was performed. A SALI analysis allowed us to identify and quantify activity cliffs, and, in this way, provided details of the structural key features that contribute to the antioxidant capacity [215]. Table 5 shows the results of the 17 compound pairs found by DataWarrior. 
Table 5. Structure-Activity Landscape Index (SALI) analysis of structurally related compounds with antioxidant capacity.

\begin{tabular}{cccccccc}
\hline Pair No & ID 1 & ID 2 & Similarity & Activity $\mathbf{1}$ & Activity $\mathbf{2}$ & Delta Activity & SALI \\
\hline 1 & $\mathbf{1 0 6}$ & $\mathbf{1 0 8}$ & 0.994 & 4.000 & 4.783 & 0.783 & 120.940 \\
2 & $\mathbf{1 0 7}$ & $\mathbf{1 0 8}$ & 0.994 & 4.000 & 4.783 & 0.783 & 120.940 \\
3 & $\mathbf{1 1 3}$ & $\mathbf{1 1 4}$ & 0.987 & 3.602 & 4.429 & 0.827 & 64.979 \\
4 & $\mathbf{1 2 5}$ & $\mathbf{1 2 6}$ & 0.962 & 3.432 & 4.745 & 1.313 & 34.102 \\
5 & $\mathbf{1 0 3}$ & $\mathbf{1 0 4}$ & 0.851 & 4.000 & 5.886 & 1.886 & 12.630 \\
6 & $\mathbf{1 3 1}$ & $\mathbf{1 3 2}$ & 0.973 & 3.856 & 4.035 & 0.179 & 6.710 \\
7 & $\mathbf{1 0 5}$ & $\mathbf{1 0 8}$ & 0.878 & 4.000 & 4.783 & 0.783 & 6.426 \\
8 & $\mathbf{1 1 3}$ & $\mathbf{1 1 5}$ & 0.809 & 3.602 & 4.558 & 0.955 & 4.993 \\
9 & $\mathbf{1 2 3}$ & $\mathbf{1 2 4}$ & 0.842 & 4.943 & 4.455 & 0.488 & 3.087 \\
10 & $\mathbf{6 1}$ & $\mathbf{6 2}$ & 0.962 & 3.313 & 3.235 & 0.079 & 2.042 \\
11 & $\mathbf{6 1}$ & $\mathbf{6 3}$ & 0.930 & 3.313 & 3.221 & 0.092 & 1.323 \\
12 & $\mathbf{1 2 9}$ & $\mathbf{1 3 0}$ & 0.962 & 3.454 & 3.492 & 0.038 & 0.994 \\
13 & $\mathbf{6 2}$ & $\mathbf{6 3}$ & 0.864 & 3.235 & 3.221 & 0.014 & 0.102 \\
14 & $\mathbf{1 3 9}$ & $\mathbf{1 4 0}$ & 1.000 & 4.298 & 4.120 & 0.178 & 0.000 \\
15 & $\mathbf{1 0 5}$ & $\mathbf{1 0 7}$ & 0.893 & 4.000 & 4.000 & 0.000 & 0.000 \\
16 & $\mathbf{1 0 5}$ & $\mathbf{1 0 6}$ & 0.893 & 4.000 & 4.000 & 0.000 & 0.000 \\
17 & $\mathbf{1 0 6}$ & $\mathbf{1 0 7}$ & 1.000 & 4.000 & 4.000 & 0.000 & NaN $^{\mathrm{a}}$ \\
\hline
\end{tabular}

As the SALI value is directly proportional to the change of the antioxidant potency, a higher SALI value indicated a higher change in bioactivity between very closely related compounds. Likewise, the SALI value coincides with the similarity value between the pair of metabolites. For this reason, 14 to 16 pairs (Table 5) exhibited null SALI values, because the metabolites either had a high similarity or a low potency change. SALI value was not possible to be calculated for the last pair (Table 5, No. 17), since no potency differences were observed for those very structurally related compounds. To visualize these results in a more user-friendly way, a dot-plot that relates the capacity folding (delta activity) against similarity is presented in Figure 11A. In the graph, moving up in each axis indicates more prominent activity cliffs. Hence, pairs 1 to 4 were plotted in the upper-right region. The cluster of structurally related compounds with the highest activity cliffs was taken as a reference to provide details of this measure. In Figure 11B, structures and SALI values for compounds 105, 106, 107 and 108 (i.e., pair numbers 1, 2, 7, 15, 16 and 17) are exhibited. The position and orientation of the para-hydroxyl groups at the aromatic ring of $\mathbf{1 0 8}$ appear to be an essential feature for the antioxidant capacity. In fact, the additional hydroxyl group appears to activate the other hydroxyl group in the para-position to be transferred for antioxidant action, due to the inductive electronic effect. This finding is not surprising because it is recognized that hydrogen-atom transfer is a major mechanism that contributed to the antioxidant capacity of phenolic-like compounds [216]. Additionally, an aromatic mesomeric effect would influence the good antioxidant capacity of $\mathbf{1 0 8}$, as the para-hydroxyl (in $p$-hydroquinone moiety) group easily promotes the formation of a $p$-benzoquinone moiety within an oxidant environment due to its reducing ability. Hence, we explored how the $H$-donor property correlated with the radical scavenging capacity in the whole subgroup of compounds. Likewise, cLogP, cLogS, $H$-acceptors, TPSA, druglikeness and irritant risk properties were included in the examination.

Finally, we observed that the molecular descriptors such as molar mass, $H$-acceptors, TPSA and $H$-donors had a significant correlation $(p<0.05)$ with the antioxidant capacity (Figure 12A). It is also important to point out that the $H$-donor property showed a higher correlation with the antioxidant capacity (Figure 12A) and as expected, it explained the function of most compounds $(68.9 \%, p=0,0174)$ (Figure 12B). Nevertheless, the antioxidant capacity of other compounds (31.1\%; Q1 and Q4) was mediated though other mechanisms, given that the exhibited antioxidant effect was regardless of the number of $H$-donors. This disparity may be related to steric accessibility, solubility and electron donors, among other chemical features of the antioxidant agent [217]. 


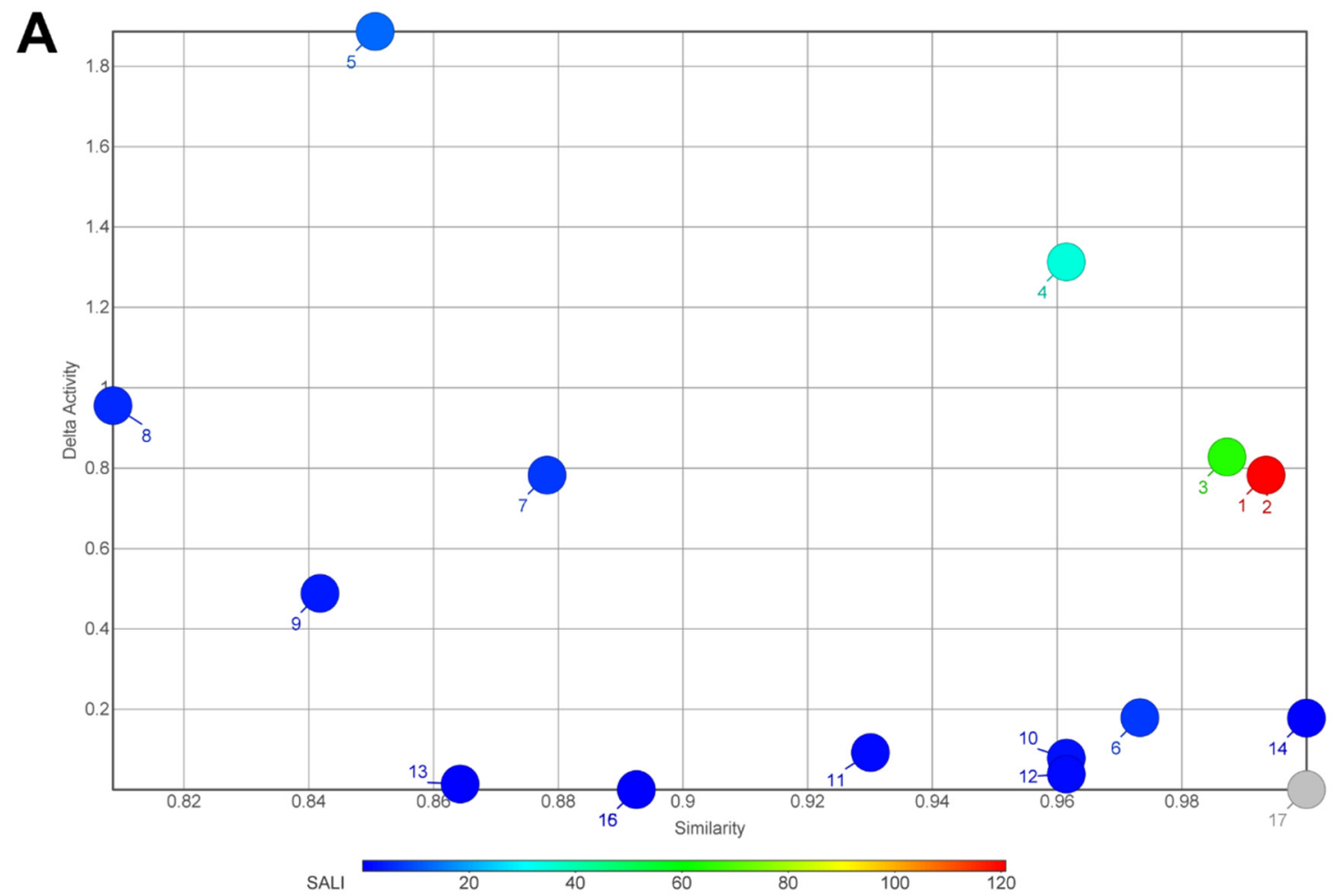

\section{B}

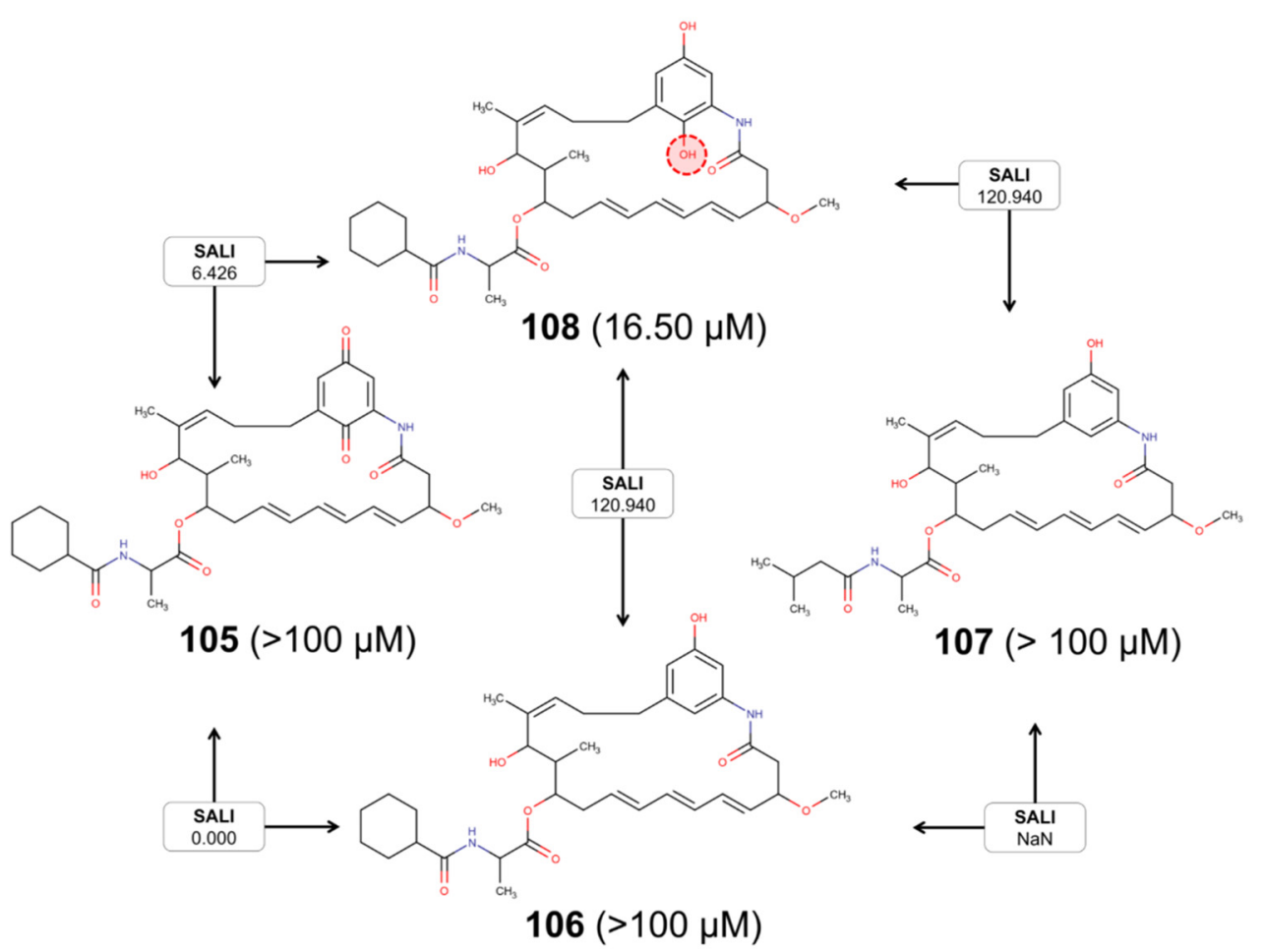

Figure 11. Pairs of structurally related compounds showing activity cliffs. A SALI analysis performed by DataWarrior identifies 17 metabolite pairs with activity cliffs. (A) For each pair of compounds, the delta of activity was plotted versus the similarity. The color scale bar indicates the SALI value from 0 (blue) to 120 (red). Each numbered label shows the pair of structurally related compounds listed in Table 5. (B) Structures and SALI values for selected compounds (i.e., 105, 106, 107 and 108 comprising the pair numbers $1,2,7,15,16$ and 17$)$. The values in parentheses indicate the $\mathrm{IC}_{50}$ experimentally calculated for each compound. Compound 108 differs from 105, 106 and 107 in the additional hydroxyl group at the aromatic ring (highlighted by the red dotted circle). 
A

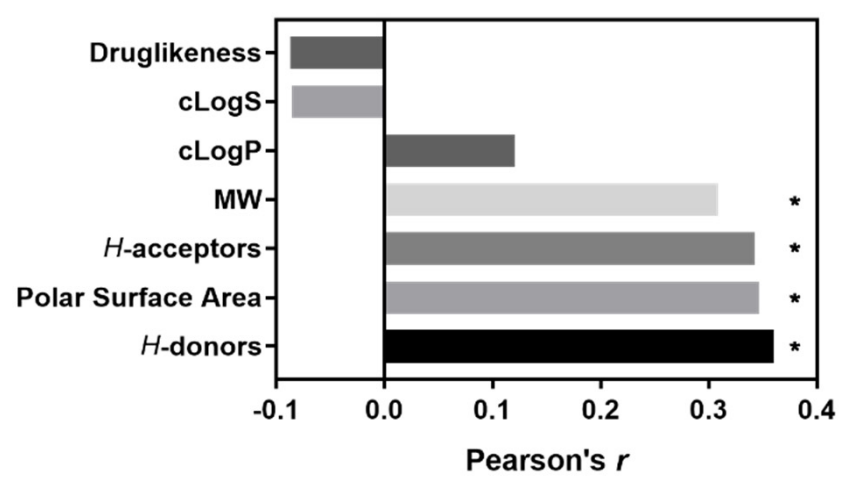

B

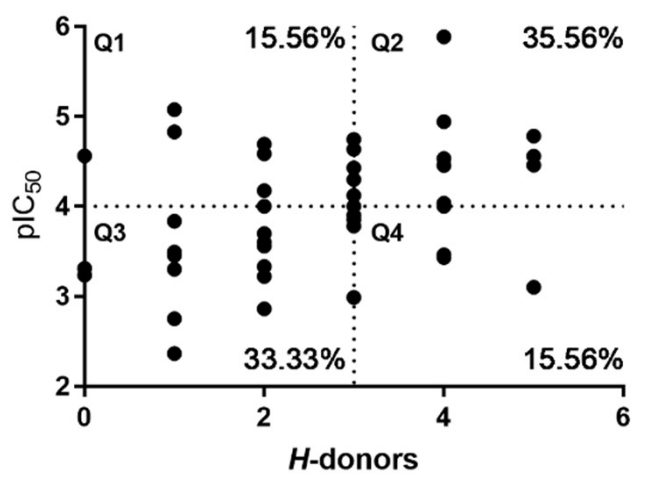

Figure 12. Correlation of molecular properties with antioxidant capacity in Streptomyces-derived metabolites. The properties druglikeness, cLogS, cLogP, molecular weight, $H$-acceptors, TPSA and $H$-donor were calculated by DataWarrior. (A) Pearson correlation coefficient between antioxidant capacity $\left(\mathrm{pIC}_{50}\right.$ ) and each calculated property. Asterisk indicates statistically significant correlation. (B) Dot plot of antioxidant capacity $\left(\mathrm{pIC}_{50}\right)$ against $H$-donor numbers. To evaluate the association of the property with the activity, a Fisher's exact test was calculated ( $p=0.0174)$. Quadrant 1 (Q1), quadrant $2(\mathrm{Q} 2)$, quadrant $3(\mathrm{Q} 3)$ and quadrant $4(\mathrm{Q} 4)$. In each quadrant, the percent of dots is presented.

\section{Discussion}

Actinobacteria belonging to the genus Streptomyces are an important source of bioactive compounds, especially antibiotic agents $[39,218]$. Furthermore, other industrially relevant bioactivities have been reported for Streptomyces-derived metabolites $[39,219]$. These microorganisms are thus a promising source for new bioactive natural products. Herein, we conducted a systematic literature review to show that Streptomyces offers a remarkable opportunity to provide metabolites with photoprotective capabilities, since there is an urgent need to find safer and eco-friendly active ingredients for sunscreens.

We first wanted to illustrate that Streptomyces can produce metabolites with photoprotection-related activities. In this literature survey, both crude extracts and pure compounds obtained from several Streptomyces strains (89 and 75 strains, respectively) exhibited UV-absorbing, antioxidant, anti-inflammatory properties. However, bearing in mind that few countries have provided studies in this field (Figure 2B), the number of photoprotective metabolite-producing Streptomyces strains might be undervalued. Moreover, because Streptomyces are ubiquitous microbes found in both terrestrial and marine environments $[218,219]$ and studies involving strains from marine habitats were scarce $(34.9 \%$, Figure 3C), it is possible to assume that the real number could be significantly higher. This finding is crucial considering that the biological diversity of Streptomyces is widely recognized not only in terms of species numbers but also in terms of the array of secondary metabolite biosynthetic genes $[218,220]$. Even within a single strain, this diversity may persist [221]. Consequently, investment in research efforts focusing on Streptomyces isolates from poorly explored environments thus far (e.g., marine habitats) is highly recommended.

On the other hand, it was found that most studies (65.1\%) employed free-living strains, overlooking that the interaction between symbiotic microbes and their hosts is a critical aspect of evolution [222]. Furthermore, these interactions play an influential factor in the evolution of the gene pool for Streptomyces specialized metabolism [49]. It is imperative to expand this type of research, involving symbiotic microorganisms from marine environments, as it was evidently the less explored condition (only eight articles evaluated Streptomyces isolated from marine organisms-two ascidians [187,189], three corals [184-186], one jellyfish [190], one sponge [183] and one starfish [188]).

Regarding chemical diversity, most of the metabolites in the compound library derived from the present review did not show shared fingerprints (Figure 6). This abundance of unique fingerprints may give an idea of the diversity of the gene clusters encoding favorably regulated biosynthetic pathways 
used by Streptomyces to produce metabolites with exclusive structural features for exhibiting both antioxidant and anti-inflammatory properties. This detail is reflected in the different kinds of active Streptomyces-derived metabolites reported in the literature (Figure 8). Nevertheless, we found that alkaloids were the most representative group of compounds with antioxidant capacity, while amides were preferably reported as anti-inflammatory compounds. These findings are consistent with several experimental records showing the antioxidant value of alkaloids [223-225]. In the same way, several studies have reported amides as naturally occurring anti-inflammatory compounds [226-228]. Nonetheless, anti-inflammatory amides exhibiting antioxidant activity have also been reported [229,230], which supports the chance to find compounds having dual antioxidant and anti-inflammatory activities. This fact, in addition to the diversified gene arrays involved in the synthesis of specialized metabolites in Streptomyces [220,221], makes these microbes a suitable source to find new and efficient photoprotective molecules.

The biological and chemical diversity of Streptomyces is convincing so far. Moreover, Streptomyces-derived metabolites also have physicochemical properties and potency comparable with reference or standard agents. For instance, comparing anti-inflammatory compounds with UV filters, the most relevant differences were in druglikeness and irritant risk (Figure 9). However, related to druglikeness, most of the Streptomyces-derived compounds fall inside the same interval to that of UV filters (Figure 9D). In contrast, the irritant risk was substantially different. Most of the UV filters were considered high risk, while only a small portion (10\%) of Streptomyces-derived compounds had the same qualification. This is an important feature because the irritant risk of the UV filters currently available in the market is a contemporary concern [212]. Thus, the fact that Streptomyces-derived compounds have been rated as none or low risk is encouraging, as it means that this requirement can be satisfactorily met.

Regarding bioactivity potency, anti-inflammatory compounds were not possible to be analyzed under such a criterion. As inflammation is a physiological response that involves several signaling pathways, there are several different methodological approaches to evaluate the anti-inflammatory activity. This feature was reflected in the literature survey, so it was a factor that limited the analysis options since the biological effects measured for each method could not be compared easily between compounds. On the other hand, the fact that several compounds have shown positive results in a variety of methods also shows that the metabolites might have different ways to produce an anti-inflammatory action. Several compounds were active at micromolar concentrations [145,147,148,162-164,175,176,178,181,188,198,199]; even more, some metabolites were as active as reference drugs used in their respective assays. Additionally, a very remarkable case is FK-506 (also known as tacrolimus). This compound was first isolated from S. tsukubaenis No. 9993, in 1987 by Kino et al. [151] and currently it is used commercially as a topical anti-inflammatory in dermatology [231]. These findings show that, in terms of anti-inflammatory compounds, Streptomyces is an option with a high probability of success at a translational level. In this matter, Streptomyces species are especially noteworthy, since their biotechnology potential on an industrial scale has already been proven [232]. Approaches such as metabolic engineering [233], metabolic flux analysis [233] and genetic manipulation [233] have been successful in improving large-scale manufacturing of Streptomyces-derived metabolites. Likewise, Streptomyces biology knowledge concerning the regulation of secondary metabolite biosynthesis is increasingly more comprehensive [234-237], which encourages bioprospecting studies on Streptomyces, with the opportunity that they will be as successful-in terms of industrial microbes-to produce photoprotective metabolites, as they have been employed for antibiotics production.

Regarding antioxidant compounds, due to the common use of the DPPH radical scavenging assay, it was possible to perform a more detailed analysis by both SPR and SAR examinations. The analysis carried out in the present review allowed us to make evident that some of the Streptomyces-derived metabolites were as active or even more active, than well-known reference antioxidants, including vitamin C, vitamin E, quercetin and rutin, among others (Table 4, Figure 10). An antioxidant agent works by the transfer of either a hydrogen atom (HAT), single electron (ET) or both [217]. 
Accordingly, the methods used to assay potential antioxidant compounds are classified as HAT-based, ET-based or mixed-mode [217]. Some authors consider DPPH radical scavenging assay as a way to assess compounds having a mixed-mode mechanism [238]. In this regard, SALI analysis made it possible to understand that HAT was the mechanism that could be involved in most of the compounds (Figure 12), according to previous publications [216]. However, considering that the results come only from the DPPH radical scavenging assay and bearing in mind that the use of more than one method is strongly encouraged [238], it is not possible to determine the mechanism and, consequently, the actual antioxidant power of these compounds. In this sense, it is important to extend the repertoire of methods to evaluate the antioxidant potential of a certain compound; this would robustly demonstrate its qualification on determining its true potential and scope as an antioxidant. Additionally, a set of distinct parameters should be included, such as kinetics, more than one solvent (e.g., hydrophilic, hydrophobic, protic and aprotic) and different types of radicals and sources. Such a profile can help to comprehensively and accurately determine the antioxidant power of a given compound, in terms of both activity and capacity [238].

The present review is valuable to support the fact that Streptomyces are active producers of photoprotective compounds. Nevertheless, their potential as UV-absorbing agents has been poorly studied $(2.1 \%$ of the publications included in the review). This fact is a meaningful regret, as many of the compounds that were included in this systematic review have conjugated systems, implying a high molar absorption coefficient, which is characteristic of UV filters used for the manufacture of sunscreens [239]. Photoprotective activity, however, goes beyond the UV-absorbing capacity and it is also related to antioxidant and anti-inflammatory activity, which are valuable for effective sunscreen formulations [240-243]. Mainly, in this study, we provide some evidence insight into the antioxidant capacity of reported compound 108, which is related to the presence of an active-reducing para-hydroquinone-like moiety, implying an interesting starting point for the investigation of the application of Streptomyces-derived metabolites as antioxidants. Accordingly, as shown in the present review, it is possible to settle that Streptomyces is a bacterial genus with outstanding potential in the development of photoprotective products. Nevertheless, further research needs to be carried out to understand the biology and metabolite production of isolates from different environments and expand the knowledge on the bio and chemodiversity of Streptomyces-related microorganisms.

\section{Methods}

\subsection{Databases and Search Strategy}

To achieve as comprehensive a literature examination as possible, the search was conducted using the following databases-Scopus, Web of Science, PubMed, EBSCOhost Research, Scielo and Sage Journals. The terms (including synonyms and related words) and Boolean operators used for each searching were defined as follows:

- Web of Science, PubMed, EBSCOhost Research, Scielo and Sage Journals:

streptomyces AND ("anti UV" OR photoaging OR photoprotection OR "photo protection" OR "sun protection" OR "sunlight protection" OR sunscreen OR sunscreening OR "UV protection" OR

"ultraviolet blocking" OR "ultraviolet shielding" OR “UV absorbing”) NOT cyanobacteria

streptomyces AND (antioxidant OR anti-inflammatory)

- Scopus:

streptomyces AND "anti UV" OR photoaging OR photoprotection OR "photo protection" OR "sun protection" OR "sunlight protection" OR sunscreen OR sunscreening OR "UV protection" OR "ultraviolet blocking" OR "ultraviolet shielding" OR "UV absorbing"

streptomyces AND antioxidant OR anti-inflammatory 


\subsection{Selection Procedure}

The selection of the articles was based on the following inclusion criteria-(a) original research articles, (b) studies on extracts or compounds derived from identified Streptomyces strains and (c) studies evaluating at least one of these activities-UV-absorbing, antioxidant and anti-inflammatory. The following were considered exclusion criteria-(a) articles were written in a language other than English, (b) compounds were not identified and (c) concentrations of compounds or extracts concentrations were not reported.

The article selection process was subdivided into two stages as follows-in the first stage, three researchers separately assessed each title and abstract in a blind process. At this time, an article was marked as potentially eligible to be included in the review when at least two studies indicated that it met the inclusion/exclusion criteria. When an article was indicated by only one researcher, a discussion within the research team was carried out to solve discrepancies. Potentially eligible articles were then examined at the full-text level. At this point, those articles that met the inclusion/exclusion criteria were finally selected for data extraction.

\subsection{Data Collection and Tabulation}

To ensure careful data collection and avoid the risk of bias, before data extraction, a pilot data acquisition form was prepared. The form was evaluated and improved by doing an exercise involving ten randomly selected items. Once the final version of the form was defined, it was used for the data acquisition of the whole set of selected articles. The data were tabulated using the form by one researcher and verified by a second researcher.

\subsection{Structure-Based Clustering}

Compounds retrieved from this systematic review were converted to SMILES notation (simplified molecular-input line-entry system) using Marvin JS (ChemAxon, Budapest, Hungary) to build a custom-made library. Due to the high chemical diversity initially found, these compounds were then clustered according to substructures using binary fingerprints. Hence, the resulting chemical space was initially filtered based on their carbon skeletons and chemical functionalities using the fragment dictionary based binary fingerprint ( FragFp), path fingerprint (PathFp) and organic functionality (OrgFunctions) descriptors implemented in Osiris DataWarrior v5.2.1 (Idorsia Pharmaceuticals Ltd., Switzerland) [203]. This substructure filtering led to the exploration of the structural similarity within the custom-made compound library. The detailed inspection of the similarity plots, in combination with metabolic pathway annotation, served as a classification of selected metabolites.

\subsection{Data Analysis}

A meta-analysis was conducted with the metabolites retrieved from the included articles. First, the metabolites were grouped according to their described biological activity. To relate the structural profile and some functional features for a plausible photoprotective-related potential regarding skin penetration and pharmaceutical and sunscreening values, a structure-property relationship analysis (SPR) was first performed. Accordingly, some common physicochemical parameters were then selected, such as molecular weight, topological polar surface area (TPSA), octanol/water partition coefficient $(\mathrm{cLog} P)$, aqueous solubility (cLogS), $H$-acceptors and $H$-donors, along with the pharmaceutical criteria druglikeness and the irritant risk was theoretically calculated using the software Osiris DataWarrior v5.2.1. Additionally, the meta-analysis was expanded through a structure-activity relationship analysis (SAR) for those compounds whose antioxidant capacity was assessed by comparable methods to each other. Both analyses were also performed using the software Osiris DataWarrior v5.2.1. 


\section{Conclusions}

Bacteria of the genus Streptomyces are recognized for their ability to produce a wide variety of bioactive secondary metabolites, most of which show antimicrobial activity. Herein, the Streptomyces-derived metabolites with UV-absorbing, anti-inflammatory and antioxidant activities are summarized and their potential as photoprotective compounds is discussed. Although the present survey did not succeed to find any compound possessing all three properties to enhance the photoprotective ability, since this three-component effect was not studied in the original papers for a certain compound, we found that these microbes synthesize compounds with diverse structures, exhibiting a trend related to anti-inflammatory and antioxidant activities. In this sense, good anti-inflammatory results were preferably composed by amides, while the better antioxidant action was produced by alkaloid-type metabolites. On the one hand, regarding anti-inflammatory action, most compounds shared physicochemical properties with FDA-approved UV filters. Unlike these, however, Streptomyces-derived metabolites were shown to have a lower risk of being irritants. On the other hand, in the antioxidant compounds, it was seen that the presence of $H$-donors is an essential feature. Despite this, available data do not give a full picture of the actual potential of Streptomyces in this field, since there remain significant ecological niches to be explored (e.g., marine symbionts). This work aimed to provide evidence of Streptomyces bacteria as promising biofactories of compounds with photoprotective related activities. These compounds may serve as chemical agents to develop safer and eco-friendly sunscreens or other sun protection products.

Supplementary Materials: The following are available online at http://www.mdpi.com/1420-3049/25/14/3221/s1, Table S1: PRISMA checklist, Table S2: List of compounds retrieved from the included papers, Table S3: Streptomyces strains source of bioactive crude extracts, Table S4: Chemical structures of retrieved compounds, Table S5: Databases search results, Figure S1: The number of papers in the literature by country of Streptomyces strain origin.

Author Contributions: Conceptualization, J.S.-S., E.C.-B., L.V. and L.D.; methodology, J.S.-S. and E.C.-B.; software, J.S.-S. and E.C.-B.; validation, E.C.-B.; formal analysis, J.S.-S.; data curation, J.S.-S., L.V. and L.D.; writing-original draft preparation, J.S.-S.; writing-review and editing, E.C.-B., L.V. and L.D.; visualization, J.S.-S.; supervision, L.V. and L.D.; funding acquisition, L.V. and L.D. All authors have read and agreed to the published version of the manuscript.

Funding: This work was funded by Minciencias (Ministerio de Ciencia, Tecnología e Innovación - Colombia -, project code 123080864186, contract 80740-168-2019) and by Universidad de La Sabana (General Research Directorate, project ING-175-2016).

Acknowledgments: Authors thank Luis F. Giraldo Cadavid for his valuable comments about the search strategy and data management and Juan David González Barbosa and Maria Fernanda Rodríguez Fonseca for the assistance during SMILES notation.

Conflicts of Interest: The authors declare no conflict of interest. The funders had no role in the design of the study; in the collection, analyses or interpretation of data; in the writing of the manuscript or in the decision to publish the results.

\section{References}

1. Gilchrest, B.A. Actinic Injury. Annu. Rev. Med. 1990, 41, 199-210. [CrossRef] [PubMed]

2. Lucas, R.M.; Norval, M.; Neale, R.E.; Young, A.R.; de Gruijl, F.R.; Takizawa, Y.; van der Leun, J.C. The consequences for human health of stratospheric ozone depletion in association with other environmental factors. Photochem. Photobiol. Sci. 2015, 14, 53-87. [CrossRef] [PubMed]

3. U.S. Department of Health and Human Services. The Surgeon General's Call to Action to Prevent Skin Cancer; U.S. Department of Health and Human Services, Office of the Surgeon General: Washington, DC, USA, 2014.

4. Mancuso, J.B.; Maruthi, R.; Wang, S.Q.; Lim, H.W. Sunscreens: An Update. Am. J. Clin. Dermatol. 2017, 18, 643-650. [CrossRef] [PubMed]

5. Serpone, N.; Dondi, D.; Albini, A. Inorganic and organic UV filters: Their role and efficacy in sunscreens and suncare products. Inorg. Chim. Acta 2007, 360, 794-802. [CrossRef]

6. Narla, S.; Lim, H.W. Sunscreen: FDA regulation, and environmental and health impact. Photochem. Photobiol. Sci. 2020, 19, 66-70. [CrossRef] [PubMed] 
7. Cole, C.; Shyr, T.; Ou-Yang, H. Metal oxide sunscreens protect skin by absorption, not by reflection or scattering. Photodermatol. Photoimmunol. Photomed. 2016, 32, 5-10. [CrossRef] [PubMed]

8. Osterwalder, U.; Hareng, L. Global UV Filters: Current Technologies and Future Innovations. In Principles and Practice of Photoprotection; Springer International Publishing: Cham, Switzerland, 2016; pp. 179-197.

9. Raffa, R.B.; Pergolizzi, J.V.; Taylor, R.; Kitzen, J.M. Sunscreen bans: Coral reefs and skin cancer. J. Clin. Pharm. Ther. 2019, 44, 134-139. [CrossRef] [PubMed]

10. Hamzelou, J. Sunscreen safety fears. N. Sci. 2019, 243, 20-21. [CrossRef]

11. Siller, A.; Blaszak, S.C.; Lazar, M.; Olasz Harken, E. Update About the Effects of the Sunscreen Ingredients Oxybenzone and Octinoxate on Humans and the Environment. Plast. Surg. Nurs. 2019, 39, 157-160. [CrossRef]

12. Krause, M.; Klit, A.; Blomberg Jensen, M.; Søeborg, T.; Frederiksen, H.; Schlumpf, M.; Lichtensteiger, W.; Skakkebaek, N.E.; Drzewiecki, K.T. Sunscreens: Are they beneficial for health? An overview of endocrine disrupting properties of UV-filters. Int. J. Androl. 2012, 35, 424-436. [CrossRef]

13. Tsui, M.M.P.; Leung, H.W.; Wai, T.C.; Yamashita, N.; Taniyasu, S.; Liu, W.; Lam, P.K.S.; Murphy, M.B. Occurrence, distribution and ecological risk assessment of multiple classes of UV filters in surface waters from different countries. Water Res. 2014, 67, 55-65. [CrossRef] [PubMed]

14. Rainieri, S.; Barranco, A.; Primec, M.; Langerholc, T. Occurrence and toxicity of musks and UV filters in the marine environment. Food Chem. Toxicol. 2017, 104, 57-68. [CrossRef]

15. Danovaro, R.; Bongiorni, L.; Corinaldesi, C.; Giovannelli, D.; Damiani, E.; Astolfi, P.; Greci, L.; Pusceddu, A. Sunscreens cause coral bleaching by promoting viral infections. Environ. Health Perspect. 2008, 116, 441-447. [CrossRef] [PubMed]

16. Downs, C.A.; Kramarsky-Winter, E.; Segal, R.; Fauth, J.; Knutson, S.; Bronstein, O.; Ciner, F.R.; Jeger, R.; Lichtenfeld, Y.; Woodley, C.M.; et al. Toxicopathological Effects of the Sunscreen UV Filter, Oxybenzone (Benzophenone-3), on Coral Planulae and Cultured Primary Cells and Its Environmental Contamination in Hawaii and the U.S. Virgin Islands. Arch. Environ. Contam. Toxicol. 2016, 70, 265-288. [CrossRef] [PubMed]

17. DeBuys, H.V.; Levy, S.B.; Murray, J.C.; Madey, D.L.; Pinnell, S.R. Modern approaches to photoprotection. Dermatol. Clin. 2000, 18, 577-590. [CrossRef]

18. Kullavanijaya, P.; Lim, H.W. Photoprotection. J. Am. Acad. Dermatol. 2005, 52, 937-958. [CrossRef]

19. Singer, S.; Karrer, S.; Berneburg, M. Modern sun protection. Curr. Opin. Pharmacol. 2019, 46, 24-28. [CrossRef]

20. Tomazelli, L.C.; de Assis Ramos, M.M.; Sauce, R.; Cândido, T.M.; Sarruf, F.D.; de Oliveira Pinto, C.A.S.; de Oliveira, C.A.; Rosado, C.; Velasco, M.V.R.; Baby, A.R. SPF enhancement provided by rutin in a multifunctional sunscreen. Int. J. Pharm. 2018, 552, 401-406. [CrossRef]

21. Batista, C.M.; Alves, A.V.F.; Queiroz, L.A.; Lima, B.S.; Filho, R.N.P.; Araújo, A.A.S.; de Albuquerque Júnior, R.L.C.; Cardoso, J.C. The photoprotective and anti-inflammatory activity of red propolis extract in rats. J. Photochem. Photobiol. B Biol. 2018, 180, 198-207. [CrossRef]

22. Bickers, D.R.; Athar, M. Oxidative stress in the pathogenesis of skin disease. J. Investig. Dermatol. 2006, 126, 2565-2575. [CrossRef]

23. Bosch, R.; Philips, N.; Suárez-Pérez, J.; Juarranz, A.; Devmurari, A.; Chalensouk-Khaosaat, J.; González, S. Mechanisms of Photoaging and Cutaneous Photocarcinogenesis, and Photoprotective Strategies with Phytochemicals. Antioxidants 2015, 4, 248-268. [CrossRef]

24. Mounessa, J.; Buntinx-Krieg, T.; Qin, R.; Dunnick, C.A.; Dellavalle, R.P. Primary and Secondary Chemoprevention of Malignant Melanoma. Am. J. Clin. Dermatol. 2016, 17, 625-634. [CrossRef] [PubMed]

25. Rodrigues, T.; Reker, D.; Schneider, P.; Schneider, G. Counting on natural products for drug design. Nat. Chem. 2016, 8, 531-541. [CrossRef] [PubMed]

26. Mahesh, S.K.; Fathima, J.; Veena, V.G. Cosmetic Potential of Natural Products: Industrial Applications. In Natural Bio-Active Compounds; Swamy, M.K., Akhtar, M.S., Eds.; Springer: Singapore, 2019; pp. 215-250. ISBN 978-981-13-7204-9.

27. Eastgate, M.D.; Schmidt, M.A.; Fandrick, K.R. On the design of complex drug candidate syntheses in the pharmaceutical industry. Nat. Rev. Chem. 2017, 1, 1-16. [CrossRef]

28. Wallace, M.A.; Cheng, Y.-Q.; Currens, G.C. Construction of a Texas Microbes-Derived New Natural Product Library for Novel Drug Discovery. In Proceedings of the Summer Research Internship Program-2017; University of North Texas: Denton, TX, USA, 2017. 
29. Chang, M.C.Y.; Keasling, J.D. Production of isoprenoid pharmaceuticals by engineered microbes. Nat. Chem. Biol. 2006, 2, 674-681. [CrossRef]

30. Demain, A.L. Microbial biotechnology. Trends Biotechnol. 2000, 18, 26-31. [CrossRef]

31. Pessôa, M.G.; Vespermann, K.A.C.; Paulino, B.N.; Barcelos, M.C.S.; Pastore, G.M.; Molina, G. Newly isolated microorganisms with potential application in biotechnology. Biotechnol. Adv. 2019, 37, 319-339. [CrossRef] [PubMed]

32. Mishra, M.; Vishwakarma, K.; Singh, J.; Jain, S.; Kumar, V.; Tripathi, D.K.; Sharma, S. Exploring the Multifaceted Role of Microbes in Pharmacology. In Microbial Biotechnology: Volume 2. Application in Food and Pharmacology; Patra, J.K., Das, G., Shin, H.-S., Eds.; Springer: Singapore, 2018; pp. 319-329. ISBN 978-981-10-7140-9.

33. Du, J.; Shao, Z.; Zhao, H. Engineering microbial factories for synthesis of value-added products. J. Ind. Microbiol. Biotechnol. 2011, 38, 873-890. [CrossRef] [PubMed]

34. Gill, S.R.; Pop, M.; DeBoy, R.T.; Eckburg, P.B.; Turnbaugh, P.J.; Samuel, B.S.; Gordon, J.I.; Relman, D.A.; Fraser-Liggett, C.M.; Nelson, K.E. Metagenomic Analysis of the Human Distal Gut Microbiome. Science 2006, 312, 1355-1359. [CrossRef]

35. Yang, X.; Xie, L.; Li, Y.; Wei, C. More than 9,000,000 Unique Genes in Human Gut Bacterial Community: Estimating Gene Numbers Inside a Human Body. PLoS ONE 2009, 4, e6074. [CrossRef]

36. Tierney, B.T.; Yang, Z.; Luber, J.M.; Beaudin, M.; Wibowo, M.C.; Baek, C.; Mehlenbacher, E.; Patel, C.J.; Kostic, A.D. The Landscape of Genetic Content in the Gut and Oral Human Microbiome. Cell Host Microbe 2019, 26, 283-295.e8. [CrossRef] [PubMed]

37. Jenke-Kodama, H.; Börner, T.; Dittmann, E. Natural Biocombinatorics in the Polyketide Synthase Genes of the Actinobacterium Streptomyces avermitilis. PLoS Comput. Biol. 2006, 2, e132. [CrossRef] [PubMed]

38. Hillenmeyer, M.E.; Vandova, G.A.; Berlew, E.E.; Charkoudian, L.K. Evolution of chemical diversity by coordinated gene swaps in type II polyketide gene clusters. Proc. Natl. Acad. Sci. USA 2015, 112, 13952-13957. [CrossRef] [PubMed]

39. Barka, E.A.; Vatsa, P.; Sanchez, L.; Gaveau-Vaillant, N.; Jacquard, C.; Meier-Kolthoff, J.P.; Klenk, H.-P.; Clément, C.; Ouhdouch, Y.; van Wezel, G.P. Taxonomy, Physiology, and Natural Products of Actinobacteria. Microbiol. Mol. Biol. Rev. 2016, 80, 1-43. [CrossRef] [PubMed]

40. Watve, M.G.; Tickoo, R.; Jog, M.M.; Bhole, B.D. How many antibiotics are produced by the genus Streptomyces? Arch. Microbiol. 2001, 176, 386-390. [CrossRef]

41. De Lima Procópio, R.E.; da Silva, I.R.; Martins, M.K.; de Azevedo, J.L.; de Araújo, J.M. Antibiotics produced by Streptomyces. Braz. J. Infect. Dis. 2012, 16, 466-471. [CrossRef] [PubMed]

42. Takahashi, Y.; Nakashima, T. Actinomycetes, an Inexhaustible Source of Naturally Occurring Antibiotics. Antibiotics 2018, 7, 45. [CrossRef]

43. Sinha, R.P.; Singh, S.P.; Häder, D.P. Database on mycosporines and mycosporine-like amino acids (MAAs) in fungi, cyanobacteria, macroalgae, phytoplankton and animals. J. Photochem. Photobiol. B Biol. 2007, 89, $29-35$. [CrossRef] [PubMed]

44. Miyamoto, K.T.; Komatsu, M.; Ikeda, H. Discovery of gene cluster for mycosporine-like amino acid biosynthesis from Actinomycetales microorganisms and production of a novel mycosporine-like amino acid by heterologous expression. Appl. Environ. Microbiol. 2014, 80, 5028-5036. [CrossRef] [PubMed]

45. Volkmann, M.; Gorbushina, A.A. A broadly applicable method for extraction and characterization of mycosporines and mycosporine-like amino acids of terrestrial, marine and freshwater origin. FEMS Microbiol. Lett. 2006, 255, 286-295. [CrossRef] [PubMed]

46. Madhusudhan, D.N.; Agsar, D.; Sulochana, M.B. Water Soluble Melanin of Streptomyces lusitanus DMZ3 Persuade Synthesis of Enhanced Bio-medically Active Silver Nanoparticles. J. Clust. Sci. 2015, 26, 1077-1089. [CrossRef]

47. Omura, S.; Ikeda, H.; Ishikawa, J.; Hanamoto, A.; Takahashi, C.; Shinose, M.; Takahashi, Y.; Horikawa, H.; Nakazawa, H.; Osonoe, T.; et al. Genome sequence of an industrial microorganism Streptomyces avermitilis: Deducing the ability of producing secondary metabolites. Proc. Natl. Acad. Sci. USA 2001, 98, 12215-12220. [CrossRef] [PubMed]

48. Romero-Rodríguez, A.; Robledo-Casados, I.; Sánchez, S. An overview on transcriptional regulators in Streptomyces. Biochim. Biophys. Acta Gene Regul. Mech. 2015, 1849, 1017-1039. [CrossRef] [PubMed] 
49. Seipke, R.F.; Kaltenpoth, M.; Hutchings, M.I. Streptomyces as symbionts: An emerging and widespread theme? FEMS Microbiol. Rev. 2012, 36, 862-876. [CrossRef] [PubMed]

50. Challis, G.L.; Hopwood, D.A. Synergy and contingency as driving forces for the evolution of multiple secondary metabolite production by Streptomyces species. Proc. Natl. Acad. Sci. USA 2003, 100, 14555-14561. [CrossRef] [PubMed]

51. Lewin, G.R.; Carlos, C.; Chevrette, M.G.; Horn, H.A.; McDonald, B.R.; Stankey, R.J.; Fox, B.G.; Currie, C.R. Evolution and Ecology of Actinobacteria and Their Bioenergy Applications. Annu. Rev. Microbiol. 2016, 70, 235-254. [CrossRef] [PubMed]

52. Moher, D.; Liberati, A.; Tetzlaff, J.; Altman, D.G. Preferred Reporting Items for Systematic Reviews and Meta-Analyses: The PRISMA Statement. PLoS Med. 2009, 6, e1000097. [CrossRef]

53. Tarkka, M.; Hampp, R. Secondary Metabolites of Soil Streptomycetes in Biotic Interactions. In Secondary Metabolites in Soil Ecology. Soil Biology; Springer: Berlin/Heidelberg, Germany, 2008; Volume 14, pp. 107-126.

54. Dharmaraj, S. Marine Streptomyces as a novel source of bioactive substances. World J. Microbiol. Biotechnol. 2010, 26, 2123-2139. [CrossRef]

55. Peres, D.D.A.; Sarruf, F.D.; de Oliveira, C.A.; Velasco, M.V.R.; Baby, A.R. Ferulic acid photoprotective properties in association with UV filters: Multifunctional sunscreen with improved SPF and UVA-PF. J. Photochem. Photobiol. B Biol. 2018, 185, 46-49. [CrossRef]

56. De Oliveira, C.A.; Peres, D.D.; Rugno, C.M.; Kojima, M.; De Oliveira Pinto, C.A.S.; Consiglieri, V.O.; Kaneko, T.M.; Rosado, C.; Mota, J.; Velasco, M.V.R.; et al. Functional photostability and cutaneous compatibility of bioactive UVA sun care products. J. Photochem. Photobiol. B Biol. 2015, 148, 154-159. [CrossRef]

57. Bhosale, H.; Bismile, P.; Kadam, T.; Shaheen, U. Antioxidant, enzyme inhibitory and antifungal activities of actinomycetes isolated from Curcuma longa rhizosphere. Int. J. Pharm. Pharm. Sci. 2016, 8, 307-311.

58. Narendhran, S.; Rajiv, P.; Vanathi, P.; Sivaraj, R. Spectroscopic analysis of bioactive compounds from Streptomyces Cavouresis KUV39: Evaluation of antioxidant and cytotoxicity activity. Int. J. Pharm. Pharm. Sci. 2014, 6, 319-322.

59. Subathra Devi, C.; Kumari, A.; Jain, N.; Naine, S.J.; Mohanasrinivasan, V. Screening of actinomycetes isolated from soil samples for antibacterial and antioxidant activity. Int. J. Pharm. Pharm. Sci. 2013, 5, 483-489.

60. Radhakrishnan, M.; Gopikrishnan, V.; Vijayalakshmi, G.; Kumar, V. In vitro antioxidant activity and antimicrobial activity against biofilm forming bacteria by the pigment from Desert soil Streptomyces sp. D25. J. Appl. Pharm. Sci. 2016, 6, 148-150. [CrossRef]

61. Kai, Z.; Xia Ling, G.; Zheng Jun, X.; Li Hua, L.; Rong Jun, C.X.J.; Hong, G.; Kai, J.; Isomaro, Y. Isolation and characterization of a novel streptomyces strain Eri11 exhibiting antioxidant activity from the rhizosphere of Rhizoma Curcumae Longae. Afr. J. Microbiol. Res. 2011, 5, 1291-1297. [CrossRef]

62. Praveen Kumar, P.; Preetam Raj, J.P.; Nimal Christhudas, I.V.S.; Sagaya Jansi, R.; Narbert Raj, M.; Agastian, P. $\alpha$-Glucosidase Inhibition and Antioxidant Properties of Streptomyces sp.: In Vitro. Appl. Biochem. Biotechnol. 2014, 172, 1687-1698. [CrossRef]

63. Lee, D.-R.; Lee, S.-K.; Choi, B.-K.; Cheng, J.; Lee, Y.-S.; Yang, S.H.; Suh, J.-W. Antioxidant activity and free radical scavenging activities of Streptomyces sp. strain MJM 10778. Asian Pac. J. Trop. Med. 2014, 7, 962-967. [CrossRef]

64. Kaur, J.; Manhas, R.K.; Rani, R.; Arora, S. Actinobacteria from soil as potential free radical scavengers. Malays. J. Microbiol. 2013, 13, 217-227.

65. Geo, H.N.; Panneerselvam, A. Studies on bioactive potential of Streptomyces spp. (KX710212). Isolated from environmental polluted sample, Ranipet, Vellore, India. Asian J. Pharm. Clin. Res. 2016, 9, 356-359. [CrossRef]

66. Prashith, K.T.R.; Dileep, N.; Syed, J.; Rakesh, K.N.; Sunita, C.M.; Onkarappa, R. Biological activities of Streptomyces species SRDP-07 isolated from soil of Thirthahalli, Karnataka, India. Int. J. Drug Dev. Res. 2013, 5, 268-285.

67. Revathy, T.; Jayasri, M.A.; Suthindhiran, K. Anti-oxidant and enzyme-inhibitory potential of marine Streptomyces. Am. J. Biochem. Biotechnol. 2013, 9, 282-290. [CrossRef]

68. Jemimah Naine, S.; Nasimunislam, N.; Vaishnavi, B.; Mohanasrinivasan, V.; Subathra Devi, C. Isolation of soil actinomycetes inhabiting amrithi forest for the potential source of bioactive compounds. Asian J. Pharm. Clin. Res. 2012, 5, 189-192. 
69. Rani, R.; Arora, S.; Kaur, J.; Manhas, R.K. Phenolic compounds as antioxidants and chemopreventive drugs from Streptomyces cellulosae strain TES17 isolated from rhizosphere of Camellia sinensis. BMC Complement. Altern. Med. 2018, 18, 1-15. [CrossRef] [PubMed]

70. Subathradevi, C.; Devi, P.; Jemimahnaine, S.; Mohanasrinivasan, V. Antibacterial and Antioxidant Property of Streptomyces cinnamonensis VITNS1 Isolated from Serkadu Region, Vellore, Tamil Nadu, India. Anti Infect. Agents 2014, 12, 206-212. [CrossRef]

71. Law, J.W.F.; Ser, H.L.; Duangjai, A.; Saokaew, S.; Bukhari, S.I.; Khan, T.M.; Ab Mutalib, N.S.; Chan, K.G.; Goh, B.H.; Lee, L.H. Streptomyces colonosanans sp. nov., a novel actinobacterium isolated from Malaysia mangrove soil exhibiting antioxidative activity and cytotoxic potential against human colon cancer cell lines. Front. Microbiol. 2017, 8, 1-15. [CrossRef] [PubMed]

72. Chakraborty, I.; Redkar, P.; Munjal, M.; Sathish Kumar, S.R.; Bhaskara Rao, K.V. Isolation and characterization of pigment producing marine actinobacteria from mangrove soil and applications of bio-pigments. Der Pharm. Lett. 2015, 7, 93-100.

73. Parimala, G.S.A.; Manon, M.V.; Karthiyaini, D.; Priyadharshini, U.; Jeeva, S.; Brindha, P. V Bioprospecting fungicidal metabolite producing marine actinomycetes from southern coastal regions of India. Int. J. Life Sci. Pharma Res. 2017, 7, 55-64.

74. Kumar, P.S.; Abdullah Al-Dhabi, N.; Duraipandiyan, V.; Balachandran, C.; Kumar, P.P.; Ignacimuthu, S. In vitro antimicrobial, antioxidant and cytotoxic properties of Streptomyces lavendulae strain SCA5. BMC Microbiol. 2014, 14, 291. [CrossRef]

75. Lertcanawanichakul, M.; Pondet, K.; Kwantep, J. In vitro antimicrobial and antioxidant activities of bioactive compounds (secondary metabolites) extracted from Streptomyces lydicus A2. J. Appl. Pharm. Sci. 2015, 5, 17-21. [CrossRef]

76. Jacob, J.; Rajendran, R.U.; Priya, S.H.; Purushothaman, J.; Saraswathy Amma, D.K.B.N. Enhanced antibacterial metabolite production through the application of statistical methodologies by a Streptomyces nogalater NIIST A30 isolated from Western Ghats forest soil. PLoS ONE 2017, 12, 1-21. [CrossRef] [PubMed]

77. Gautham, S.A.; Onkarappa, R. In vitro antioxidant activity of metabolite from Streptomyces fradiae strain GOS1. Int. J. Drug Dev. Res. 2013, 5, 235-244.

78. Gautham, S.A.; Onkarappa, R.; Kuppast, I.J. Pharmacological activities of metabolite from Streptomyces fradiae strain GOS 1. Int. J. Chem. Sci. 2013, 11, 583-590.

79. Lee, S.K.; Lee, D.R.; Choi, B.K.; Palaniyandi, S.A.; Yang, S.H.; Suh, J.W. Glutathione S-transferase pi (GST-pi) inhibition and anti-inflammation activity of the ethyl acetate extract of Streptomyces sp. strain MJM 8637. Saudi J. Biol. Sci. 2015, 22, 744-751. [CrossRef] [PubMed]

80. Saini, P.; Gangwar, M. Enzyme and free radical inhibitory potentials of ethyl acetate extract of endophytic actinomycete from Syzygium cumini. Indian J. Biochem. Biophys. 2017, 54, 207-213.

81. Akshatha, J.V.; Prakash, H.S.; Nalini, M.S. Actinomycete Endophytes from the Ethno Medicinal Plants of Southern India: Antioxidant Activity and Characterization Studies. J. Biol. Act. Prod. Nat. 2016, 6, 166-172. [CrossRef]

82. Nafis, A.; Kasrati, A.; Azmani, A.; Ouhdouch, Y.; Hassani, L. Endophytic actinobacteria of medicinal plant Aloe vera: Isolation, antimicrobial, antioxidant, cytotoxicity assays and taxonomic study. Asian Pac. J. Trop. Biomed. 2018, 8, 513-518. [CrossRef]

83. Wang, L.; Qiu, P.; Long, X.F.; Zhang, S.; Zeng, Z.G.; Tian, Y.Q. Comparative analysis of chemical constituents, antimicrobial and antioxidant activities of ethylacetate extracts of Polygonum cuspidatum and its endophytic actinomycete, Streptomyces sp. A0916. Chin. J. Nat. Med. 2016, 14, 117-123. [CrossRef]

84. Axenov-Gribanov, D.V.; Voytsekhovskaya, I.V.; Rebets, Y.V.; Tokovenko, B.T.; Penzina, T.A.; Gornostay, T.G.; Adelshin, R.V.; Protasov, E.S.; Luzhetskyy, A.N.; Timofeyev, M.A. Actinobacteria possessing antimicrobial and antioxidant activities isolated from the pollen of scots pine (Pinus sylvestris) grown on the Baikal shore. Antonie Van Leeuwenhoek 2016, 109, 1307-1322. [CrossRef]

85. Nimal Christhudas, I.V.S.; Praveen Kumar, P.; Agastian, P. In Vitro $\alpha$-Glucosidase Inhibition and Antioxidative Potential of an Endophyte Species (Streptomyces sp. Loyola UGC) Isolated from Datura stramonium L. Curr. Microbiol. 2013, 67, 69-76. [CrossRef]

86. Jasim, B.; Soumya, R.; Jyothis, M.; Radhakrishnan, E.K. Exploration of actinomycetes endophytically associated with Piper nigrum for potential bioactivity. J. Microbiol. Biotechnol. Food Sci. 2015, 4, 282-286. [CrossRef] 
87. Tanvir, R.; Sajid, I.; Hasnain, S. Biotechnological potential of endophytic actinomycetes associated with Asteraceae plants: Isolation, biodiversity and bioactivities. Biotechnol. Lett. 2014, 36, 767-773. [CrossRef] [PubMed]

88. Khanam, W.; Vootla, S.K. Comparative study of Ocimum basillicum and its endophytic actinomycetes Streptomyces flavoviridis a3wk: Evaluation of antioxidant, anti-inflammatory and antimicrobial activity. Int. J. Pharm. Sci. Res. 2018, 9, 1023-1034. [CrossRef]

89. Ser, H.L.; Tan, L.T.H.; Palanisamy, U.D.; Abd Malek, S.N.; Yin, W.F.; Chan, K.G.; Goh, B.H.; Lee, L.H. Streptomyces antioxidans sp. nov., a novel mangrove soil actinobacterium with antioxidative and neuroprotective potentials. Front. Microbiol. 2016, 7, 1-14. [CrossRef] [PubMed]

90. Veena, S.; Swetha, D.; Karthik, L.; Bhaskara Rao, K.V. Assessment of anti-typhoid and antioxidant activity of marine actinobacteria isolated from Chennai marine sediments. Der Pharm. Lett. 2016, 8, 166-172.

91. Jemimah Naine, S.; Subathra Devi, C.; Mohanasrinivasan, V.; Vaishnavi, B. Antimicrobial, antioxidant and cytotoxic activity of marine Streptomyces parvulus VITJS11 crude extract. Braz. Arch. Biol. Technol. 2015, 58, 198-207. [CrossRef]

92. Ser, H.L.; Mutalib, N.S.A.; Yin, W.F.; Chan, K.G.; Goh, B.H.; Lee, L.H. Evaluation of antioxidative and cytotoxic activities of Streptomyces pluripotens MUSC 137 isolated from mangrove soil in Malaysia. Front. Microbiol. 2015, 6, 1-11. [CrossRef] [PubMed]

93. Selvakumar, J.; Chandrasekaran, S.; Vaithilingam, M. Bio prospecting of marine-derived Streptomyces spectabilis VITJS10 and exploring its cytotoxicity against human liver cancer cell lines. Pharmacogn. Mag. 2015, 11, 469. [CrossRef]

94. Mandal, S.; Divya, V.S.; Rao, K.V.B. Bioactive potential of Streptomyces variabilis-DV-35 isolated from thottada marine sediments, Kannur, Kerala. Asian J. Pharm. Clin. Res. 2016, 9, 67-71. [CrossRef]

95. Eva, S.M.; Baraka, S.; Ken, H.M.M. Cytotoxicity and antioxidant activity of a Streptomyces sp. from mangrove sediments of dar es salaam, Tanzania. Int. J. Pharm. Pharm. Sci. 2014, 6, 563-566.

96. Karthik, L.; Kumar, G.; Rao, K.V.B. Antioxidant activity of newly discovered lineage of marine actinobacteria. Asian Pac. J. Trop. Med. 2013, 6, 325-332. [CrossRef]

97. Tan, L.T.H.; Chan, K.G.; Khan, T.M.; Bukhari, S.I.; Saokaew, S.; Duangjai, A.; Pusparajah, P.; Lee, L.H.; Goh, B.H. Streptomyces sp. MUM212 as a source of antioxidants with radical scavenging and metal chelating properties. Front. Pharmacol. 2017, 8, 1-18. [CrossRef]

98. Tan, L.T.H.; Ser, H.L.; Yin, W.F.; Chan, K.G.; Lee, L.H.; Goh, B.H. Investigation of antioxidative and anticancer potentials of Streptomyces sp. MUM256 isolated from Malaysia mangrove soil. Front. Microbiol. 2015, 6. [CrossRef] [PubMed]

99. Tan, L.T.H.; Chan, K.G.; Pusparajah, P.; Yin, W.F.; Khan, T.M.; Lee, L.H.; Goh, B.H. Mangrove derived Streptomyces sp. MUM265 as a potential source of antioxidant and anticolon-cancer agents. BMC Microbiol. 2019, 19, 1-16. [CrossRef] [PubMed]

100. Tan, L.T.H.; Chan, K.G.; Chan, C.K.; Khan, T.M.; Lee, L.H.; Goh, B.H. Antioxidative potential of a Streptomyces sp. MUM292 isolated from mangrove soil. Biomed. Res. Int. 2018, 2018. [CrossRef] [PubMed]

101. Subramanian, D.; Kim, M.S.; Kim, D.H.; Heo, M.S. Isolation, characterization, antioxidant, antimicrobial and cytotoxic effect of marine Actinomycete, Streptomyces carpaticus MK-01, against fish pathogens. Braz. Arch. Biol. Technol. 2017, 60, 1-9. [CrossRef]

102. Kamala, K.; Karuppiah, V.; Sivakumar, K. Comparative evaluation of in vitro antioxidant potent of the marine actinobacteria from gulf of Mannar Biosphere Reserve. Int. J. Pharma Bio Sci. 2013, 4, 207-216.

103. Sengupta, S.; Pramanik, A.; Ghosh, A.; Bhattacharyya, M. Antimicrobial activities of actinomycetes isolated from unexplored regions of Sundarbans mangrove ecosystem. BMC Microbiol. 2015, 15, 170. [CrossRef]

104. Almasi, F.; Mohammadipanah, F.; Adhami, H.R.; Hamedi, J. Introduction of marine-derived Streptomyces sp. UTMC 1334 as a source of pyrrole derivatives with anti-acetylcholinesterase activity. J. Appl. Microbiol. 2018, 125, 1370-1382. [CrossRef] [PubMed]

105. Jemimah Naine, S.; Subathra Devi, C.; Mohanasrinivasan, V.; George Priya Doss, C. Bioactivity of Marine Streptomyces sp. VITJS4: Interactions of Cytotoxic Phthalate Derivatives with Human Topoisomerase II $\alpha$ : An In Silico Molecular Docking Analysis. Interdiscip. Sci. Comput. Life Sci. 2018, 10, 261-270. [CrossRef] [PubMed] 
106. Duraikannu, D.; Chandrasekaran, D.S.; Selvakumar, N.J.; Vaithilingam, M. A Preliminary Study of In vitro Antioxidant and Antibacterial Activity of Streptomyces gancidicus VITSD1 Isolated from Marine Soil. Curr. Bioact. Compd. 2014, 10, 292-297. [CrossRef]

107. Raghava Rao, K.V.; Raghava Rao, T. Molecular characterization and its antioxidant activity of a newly isolated Streptomyces coelicoflavus BC 01 from mangrove soil. J. Young Pharm. 2013, 5, 121-126. [CrossRef] [PubMed]

108. Siddharth, S.; Vittal, R. Evaluation of Antimicrobial, Enzyme Inhibitory, Antioxidant and Cytotoxic Activities of Partially Purified Volatile Metabolites of Marine Streptomyces sp.S2A. Microorganisms 2018, 6, 72. [CrossRef] [PubMed]

109. Singhania, M.; Ravichander, P.; Swaroop, S.; Naine Selvakumar, J.; Vaithilingam, M.; Devi Chandrasekaran, S. Anti-bacterial and anti-oxidant property of Streptomyces laurentii VITMPS isolated from marine soil. Curr. Bioact. Compd. 2016, 13, 78-81. [CrossRef]

110. Ser, H.L.; Palanisamy, U.D.; Yin, W.F.; Chan, K.G.; Goh, B.H.; Lee, L.H. Streptomyces malaysiense sp. nov.: A novel Malaysian mangrove soil actinobacterium with antioxidative activity and cytotoxic potential against human cancer cell lines. Sci. Rep. 2016, 6, 1-12. [CrossRef] [PubMed]

111. Ser, H.L.; Palanisamy, U.D.; Yin, W.F.; Abd Malek, S.N.; Chan, K.G.; Goh, B.H.; Lee, L.H. Presence of antioxidative agent, Pyrrolo [1,2-a]pyrazine-1,4-dione, hexahydro- in newly isolated Streptomyces mangrovisoli sp. nov. Front. Microbiol. 2015, 6, 1-11. [CrossRef] [PubMed]

112. Law, J.W.F.; Ser, H.L.; Ab Mutalib, N.S.; Saokaew, S.; Duangjai, A.; Khan, T.M.; Chan, K.G.; Goh, B.H.; Lee, L.H. Streptomyces monashensis sp. nov., a novel mangrove soil actinobacterium from East Malaysia with antioxidative potential. Sci. Rep. 2019, 9, 1-18. [CrossRef] [PubMed]

113. Tangjitjaroenkun, J. Evaluation of antioxidant, antibacterial, and gas chromatography-mass spectrometry analysis of ethyl acetate extract of streptomyces omiyaensis SCH2. Asian J. Pharm. Clin. Res. 2018, 11, 271-276. [CrossRef]

114. Sanjivkumar, M.; Babu, D.R.; Suganya, A.M.; Silambarasan, T.; Balagurunathan, R.; Immanuel, G. Investigation on pharmacological activities of secondary metabolite extracted from a mangrove associated actinobacterium Streptomyces olivaceus (MSU3). Biocatal. Agric. Biotechnol. 2016, 6, 82-90. [CrossRef]

115. Pooja, S.; Aditi, T.; Naine, S.J.; Subathra Devi, C. Bioactive compounds from marine Streptomyces sp. VITPSA as therapeutics. Front. Biol. 2017, 12, 280-289. [CrossRef]

116. El-Shenawy, N.S. Effect of Streptomyces 23-2B metabolites on hepatic lipid peroxidation and some antioxidant parameters in Wister rats. World J. Microbiol. Biotechnol. 2010, 26, 2185-2191. [CrossRef]

117. Gozari, M.; Bahador, N.; Jassbi, A.R.; Mortazavi, M.S.; Eftekhar, E. Antioxidant and cytotoxic activities of metabolites produced by a new marine Streptomyces sp. isolated from the sea cucumber Holothuria leucospilota. Iran. J. Fish. Sci. 2018, 17, 413-426. [CrossRef]

118. Lertcanawanichakul, M.; Chawawisit, K.; Pondet, K.; Kwantep, J. Quantitation of total phenolic contents of bioactive compounds fractions Streptomyces species. Int. J. PharmTech Res. 2015, 7, 320-324.

119. Latha, Y.; Vasavithirumalanadhuni, V.M.; Devi, P.U.M. In vivo anti-inflammatory activity of ethyl acetate extract derived from marine Streptomyces carpaticus. Int. J. Pharm. Sci. Res. 2017, 8, 5221-5226. [CrossRef]

120. Zhao, H. Scaffold selection and scaffold hopping in lead generation: A medicinal chemistry perspective. Drug Discov. Today 2007, 12, 149-155. [CrossRef] [PubMed]

121. Kato, S.; Shindo, K.; Kawai, H.; Odagawa, A.; Matsuoka, M.; Mochizuki, J. Pyrrolostatin, a novel lipid peroxidation inhibitor from Streptomyces chrestomyceticus. Taxonomy, fermentation, isolation, structure elucidation and biological properties. J. Antibiot. 1993, 46, 892-899. [CrossRef] [PubMed]

122. Kim, W.; Kim, J.; Kim, C.-J.; Lee, K.-H.; Yoo, I.-D. Benzastatins A, B, C, and D: New Free Radical Scavengers from Streptomyces nitrosporeus 30643. I. Taxonomy, Fermentation, Isolation, Physico-chemical Properties and Biological Activities. J. Antibiot. 1996, 49, 20-25. [CrossRef] [PubMed]

123. Yang, L.; Mahal, A.; Liu, Y.; Li, H.; Wu, P.; Xue, J.; Xu, L.; Wei, X. Two new 2,5-diketopiperazines produced by Streptomyces sp. SC0581. Phytochem. Lett. 2017, 20, 89-92. [CrossRef]

124. El Sayed, O.H.; Asker, M.M.S.; Swelim, M.A.; Abbas, I.H.; Attwa, A.I.; El Awady, M.E. Production of hydroxy marilone C as a bioactive compound from Streptomyces badius. J. Genet. Eng. Biotechnol. 2016, 14, 161-168. [CrossRef] 
125. Izumikawa, M.; Satou, R.; Motohashi, K.; Nagai, A.; Ohnishi, Y.; Takagi, M.; Shin-Ya, K. Naphthoquinone-like polyketide isolated from Streptomyces sp. RI-77 and its predicted biosynthetic pathway. J. Nat. Prod. 2011, 74, 2588-2591. [CrossRef]

126. Jaivel, N.; Uvarani, C.; Rajesh, R.; Velmurugan, D.; Marimuthu, P. Natural occurrence of organofluorine and other constituents from Streptomyces sp. TC1. J. Nat. Prod. 2014, 77, 2-8. [CrossRef]

127. Kawahara, T.; Izumikawa, M.; Otoguro, M.; Yamamura, H.; Hayakawa, M.; Takagi, M.; Shin-Ya, K. JBIR-94 and JBIR-125, antioxidative phenolic compounds from Streptomyces sp. R56-07. J. Nat. Prod. 2012, 75, 107-110. [CrossRef] [PubMed]

128. Komoda, T.; Saeki, N.; Koseki, Y.; Kiyota, H. 12T061A and 12T061C, two new julichrome family compounds, as radical scavengers from Streptomyces sp. J. Gen. Appl. Microbiol. 2016, 62, 1-6. [CrossRef] [PubMed]

129. Kim, K.J.; Kim, M.A.; Jung, J.H. Antitumor and antioxidant activity of protocatechualdehyde produced from Streptomyces lincolnensis M-20. Arch. Pharm. Res. 2008, 31, 1572-1577. [CrossRef] [PubMed]

130. Kim, K.J.; Lee, J.H.; Yang, Y.J. Effect of interaction between protocatechualdehyde produced from Streptomyces lincolnensis M-20 and copper ions on antioxidant and pro-oxidant activities. Korean J. Microbiol. 2014, 50, 22-26. [CrossRef]

131. Sugiyama, Y.; Oya, A.; Kudo, T.; Hirota, A. Surugapyrone A from Streptomyces coelicoflavus strain usf-6280 as a new dpph radical-scavenger. J. Antibiot. 2010, 63, 365-369. [CrossRef] [PubMed]

132. Sugiyama, Y.; Watanabe, K.; Hirota, A. Surugapyrroles A and B, two new N-hydroxypyrroles, as DPPH radical-scavengers from Streptomyces sp. USF-6280 strain. Biosci. Biotechnol. Biochem. 2009, 73, 230-232. [CrossRef] [PubMed]

133. Komiyama, K.; Funayama, S.; Anraku, Y.; Mita, A.; Takahashi, Y.; Omura, S. Isolation of isoflavonoids possessing antioxidant activity from the fermentation broth of Streptomyces sp. J. Antibiot. 1989, 42, 1344-1349. [CrossRef]

134. Solecka, J.; Guśpiel, A.; Postek, M.; Ziemska, J.; Kawęcki, R.; Łęczycka, K.; Osior, A.; Pietrzak, B.; Pypowski, K.; Wyrzykowska, A. New derivatives of 3,4-dihydroisoquinoline-3-carboxylic acid with free-radical scavenging, d-amino acid oxidase, acetylcholinesterase and butyrylcholinesterase inhibitory activity. Molecules 2014, 19, 15866-15890. [CrossRef] [PubMed]

135. Guśpiel, A.; Ziemska, J.; Cześcik, A.; Kawecki, R.; Solecka, J. Intracellular antioxidant activity of a Streptomyces sp. 8812 secondary metabolite, 6,7-dihydroxy-3,4-dihydroisoquinoline-3-carboxylic acid, and its synthetic derivatives. Acta Pol. Pharm. Drug Res. 2016, 73, 645-651.

136. Kim, W.G.; Ryoo, I.J.; Yun, B.S.; Shin-ya, K.; Seto, H.; Yoo, I.D. New diphenazines with neuronal cell protecting activity, phenazostatins A and B, produced by Streptomyces sp. J. Antibiot. 1997, 50, 715-721. [CrossRef]

137. Shinichiro, K.; Kazutoshi, S.; Yuji, Y.; Michiko, M.; Hiroyuki, K.; Junichiro, M. Phenazoviridin, a novel free radical scavenger from Streptomyces sp. Taxonomy, fermentation, isolation, structure elucidation and biological properties. J. Antibiot. 1993, 46, 1485-1493. [CrossRef]

138. Chang, H.B.; Kim, J.H. Antioxidant properties of dihydroherbimycin A from a newly isolated Streptomyces sp. Biotechnol. Lett. 2007, 29, 599-603. [CrossRef] [PubMed]

139. Morimitsu, Y.; Hirota, A. Ansamycin Antibiotics as Free Radical Scavengers Isolated from Streptomyces by Using the Bactericidal Action of the Hydroxyl Radical. Biosci. Biotechnol. Biochem. 1996, 60, 1507-1509. [CrossRef] [PubMed]

140. Jaivel, N.; Rajesh, R.; Uvarani, C.; Marimuthu, P. In vitro antimicrobial evaluation of compound derived from Streptomyces sp. TC1 against xanthomonas oryzae pv. Oryzae. J. Pure Appl. Microbiol. 2014, 8, 1299-1310.

141. Kato, S.; Kawasaki, T.; Urata, T.; Mochizuki, J. In vitro and ex vivo free radical scavenging activities of carazostatin, carbazomycin B and their derivatives. J. Antibiot. 1993, 46, 1859-1865. [CrossRef]

142. Stankovic, N.; Radulovic, V.; Petkovic, M.; Vuckovic, I.; Jadranin, M.; Vasiljevic, B.; Nikodinovic-Runic, J. Streptomyces sp. JS520 produces exceptionally high quantities of undecylprodigiosin with antibacterial, antioxidative, and UV-protective properties. Appl. Microbiol. Biotechnol. 2012, 96, 1217-1231. [CrossRef]

143. Sajjad, W.; Ahmad, S.; Aziz, I.; Azam, S.S.; Hasan, F.; Shah, A.A. Antiproliferative, antioxidant and binding mechanism analysis of prodigiosin from newly isolated radio-resistant Streptomyces sp. strain WMA-LM31. Mol. Biol. Rep. 2018, 45, 1787-1798. [CrossRef]

144. Deng, H.; Zhang, N.; Wang, Y.; Chen, J.; Shen, J.; Wang, Z.; Xu, R.; Zhang, J.; Song, D.; Li, D. S632A3, a new glutarimide antibiotic, suppresses lipopolysaccharide-induced pro-inflammatory responses via inhibiting the activation of glycogen synthase kinase 3B. Exp. Cell Res. 2012, 318, 2592-2603. [CrossRef] 
145. Usuki, Y.; Ishii, S.; Ijiri, M.; Yoshida, K.I.; Satoh, T.; Horigome, S.; Yoshida, I.; Mishima, T.; Fujita, K.I. Evaluation of Inhibitory Activities of UK-2A, an Antimycin-Type Antibiotic, and Its Synthetic Analogues against the Production of Anti-inflammatory Cytokine IL-4. J. Nat. Prod. 2018, 81, 2590-2594. [CrossRef]

146. Nakayama, O.; Yagi, M.; Tanaka, M.; Kiyoto, S.; Uchida, I.; Hashimoto, M.; Okuhara, M.; Kohsaka, M. WS-7528, a new isoflavanone with estrogen activity isolated from Streptomyces sp. No. 7528. Taxonomy, fermentation, isolation, physico-chemical properties and biological activities. J. Antibiot. 1990, 43, 1394-1402. [CrossRef]

147. Petříčková, K.; Pospíšil, S.; Kuzma, M.; Tylová, T.; Jágr, M.; Tomek, P.; Chroňáková, A.; Brabcová, E.; Anděra, L.; Krištůfek, V.; et al. Biosynthesis of Colabomycin E, a New Manumycin-Family Metabolite, Involves an Unusual Chain-Length Factor. ChemBioChem 2014, 15, 1334-1345. [CrossRef] [PubMed]

148. Graziani, E.I.; Ritacco, F.V.; Bernan, V.S.; Telliez, J.-B. Phaeochromycins A-E, Anti-inflammatory Polyketides Isolated from the Soil Actinomycete Streptomyces phaeochromogenes LL-P018. J. Nat. Prod. 2005, 68, 1262-1265. [CrossRef] [PubMed]

149. Gullo, V.; Conover, M.; Cooper, R.; Federbush, C.; Horan, A.C.; Kung, T.; Marquez, J.; Patel, M.; Watnick, A. Sch 36605, a novel anti-inflammatory compound. Taxonomy, fermentation, isolation and biological properties. J. Antibiot. 1988, 41, 20-24. [CrossRef] [PubMed]

150. Kino, T.; Hatanaka, H.; Hashimoto, M.; Nishiyama, M.; Goto, T.; Okuhara, M.; Kohsaka, M.; Aoki, H.; Imanaka, H. FK-506, a novel immunosuppressant isolated from a Streptomyces. I. Fermentation, isolation, and physico-chemical and biological characteristics. J. Antibiot. 1987, 40, 1249-1255. [CrossRef] [PubMed]

151. Kino, T.; Hatanaka, H.; Miyata, S.; Inamura, N.; Nishiyama, M.; Yajima, T.; Goto, T.; Okuhara, M.; Kohsaka, M.; Aoki, H.; et al. Fk-506, A Novel Immunosuppressant Isolated From A Streptomyces II. Immunosuppressive Effect Of Fk-506 In Vitro. J. Antibiot. 1987, 40, 1256-1265. [CrossRef] [PubMed]

152. Pereira, R.; Santos Medeiros, Y.; Fröde, T.S. Antiinflammatory effects of Tacrolimus in a mouse model of pleurisy. Transpl. Immunol. 2006, 16, 105-111. [CrossRef] [PubMed]

153. Vigil, S.V.G.; de Liz, R.; Medeiros, Y.S.; Fröde, T.S. Efficacy of tacrolimus in inhibiting inflammation caused by carrageenan in a murine model of air pouch. Transpl. Immunol. 2008, 19, 25-29. [CrossRef]

154. Lee, S.J.; Kim, H.P.; Park, B.K.; Ahn, S.C.; Lee, H.S.; Ahn, J.S. Topical anti-inflammatory activity of dianemycin isolated from Streptomyces sp. MT 2705-4. Arch. Pharm. Res. 1997, 20, 372-374. [CrossRef] [PubMed]

155. Hori, R.; Yamaguchi, K.; Sato, H.; Watanabe, M.; Tsutsumi, K.; Iwamoto, S.; Abe, M.; Onodera, H.; Nakamura, S.; Nakai, R. The discovery and characterization of K-563, a novel inhibitor of the Keap1/Nrf2 pathway produced by Streptomyces sp. Cancer Med. 2019, 8, 1157-1168. [CrossRef]

156. Jiménez, J.T.; Sturdíková, M.; Brezová, V.; Svajdlenka, E.; Novotová, M. Screening of mutant strain Streptomyces mediolani sp. AC37 for (-)-8-O-methyltetrangomycin production enhancement. J. Microbiol. 2012, 50, 1014-1023. [CrossRef] [PubMed]

157. Taechowisan, T.; Chaisaeng, S.; Phutdhawong, W.S. Antibacterial, antioxidant and anticancer activities of biphenyls from Streptomyces sp. BO-07: An endophyte in Boesenbergia rotunda (L.) Mansf A. Food Agric. Immunol. 2017, 28, 1330-1346. [CrossRef]

158. Taechowisan, T.; Singtotong, C.; Phutdhawong, W.S. Antibacterial and antioxidant activities of acetogenins from Streptomyces sp. VE2; an endophyte in Vernonia cinerea (L.) less. J. Appl. Pharm. Sci. 2016, 6, 67-72. [CrossRef]

159. Yang, Y.; Yang, X.; Zhang, Y.; Zhou, H.; Zhang, J.; Xu, L.; Ding, Z. A new daidzein derivative from endophytic Streptomyces sp. YIM 65408. Nat. Prod. Res. 2013, 27, 1727-1731. [CrossRef] [PubMed]

160. Yang, X.; Peng, T.; Yang, Y.; Li, W.; Xiong, J.; Zhao, L.; Ding, Z. Antimicrobial and antioxidant activities of a new benzamide from endophytic Streptomyces sp. YIM 67086. Nat. Prod. Res. 2015, 29, 331-335. [CrossRef] [PubMed]

161. Zhou, H.; Yang, Y.; Peng, T.; Li, W.; Zhao, L.; Xu, L.; Ding, Z. Metabolites of Streptomyces sp., an endophytic actinomycete from Alpinia oxyphylla. Nat. Prod. Res. 2014, 28, 265-267. [CrossRef] [PubMed]

162. Hong, S.H.; Ban, Y.H.; Byun, W.S.; Kim, D.; Jang, Y.J.; An, J.S.; Shin, B.; Lee, S.K.; Shin, J.; Yoon, Y.J.; et al. Camporidines A and B: Antimetastatic and Anti-inflammatory Polyketide Alkaloids from a Gut Bacterium of Camponotus kiusiuensis. J. Nat. Prod. 2019, 82, 903-910. [CrossRef]

163. Ma, J.; Lei, H.; Chen, X.; Bi, X.; Jiang, Y.; Han, L.; Huang, X. New anti-inflammatory metabolites produced by Streptomyces violaceoruber isolated from Equus burchelli feces. J. Antibiot. 2017, 70, 991-994. [CrossRef] 
164. Ma, J.; Cao, B.; Liu, C.; Guan, P.; Mu, Y.; Jiang, Y.; Han, L.; Huang, X. Actinofuranones D-I from a lichen-associated actinomycetes, streptomyces gramineus, and their anti-inflammatory effects. Molecules 2018, 23, 2393. [CrossRef]

165. Ma, J.; Cao, B.; Chen, X.; Xu, M.; Bi, X.; Guan, P.; Jiang, Y.; Xu, J.; Han, L.; Huang, X. Violacin A, a new chromanone produced by Streptomyces violaceoruber and its anti-inflammatory activity. Bioorg. Med. Chem. Lett. 2018, 28, 947-951. [CrossRef]

166. Taechowisan, T.; Lu, C.; Shen, Y.; Lumyong, S. Anti-inflammatory effects of 4-arylcoumarins in LPS-induced murine macrophage RAW 264.7 cells. Pharm. Biol. 2006, 44, 576-580. [CrossRef]

167. Taechowisan, T.; Wanbanjob, A.; Tuntiwachwuttikul, P.; Liu, J. Anti-inflammatory activity of lansais from endophytic Streptomyces sp. SUC1 in LPS-induced RAW 264.7 cells. Food Agric. Immunol. 2009, 20, 67-77. [CrossRef]

168. Taechowisan, T.; Wanbanjob, A.; Tuntiwachwuttikul, P.; Liu, J. Anti-inflammatory effects of lansai C and D cause inhibition of STAT-1 and NF-kB activations in LPS-induced RAW 264.7 cells. Food Agric. Immunol. 2010, 21, 57-64. [CrossRef]

169. Saurav, K.; Kannabiran, K. Cytotoxicity and antioxidant activity of 5-(2,4-dimethylbenzyl)pyrrolidin-2-one extracted from marine Streptomyces VITSVK5 spp. Saudi J. Biol. Sci. 2012, 19, 81-86. [CrossRef] [PubMed]

170. Arumugam, M.; Mitra, A.; Jaisankar, P.; Dasgupta, S.; Sen, T.; Gachhui, R.; Kumar Mukhopadhyay, U.; Mukherjee, J. Isolation of an unusual metabolite 2-allyloxyphenol from a marine actinobacterium, its biological activities and applications. Appl. Microbiol. Biotechnol. 2010, 86, 109-117. [CrossRef] [PubMed]

171. Naine, S.J.; Devi, C.S.; Mohanasrinivasan, V.; Doss, C.G.P.; Kumar, D.T. Binding and molecular dynamic studies of sesquiterpenes (2R-acetoxymethyl-1,3,3-trimethyl-4t-(3-methyl-2-buten-1-yl)-1t-cyclohexanol) derived from marine Streptomyces sp. VITJS8 as potential anticancer agent. Appl. Microbiol. Biotechnol. 2016, 100, 2869-2882. [CrossRef]

172. Alvarino, R.; Alonso, E.; Lacret, R.; Oves-Costales, D.; Genilloud, O.; Reyes, F.; Alfonso, A.; Botana, L.M. Caniferolide A, a Macrolide from Streptomyces caniferus, Attenuates Neuroinflammation, Oxidative Stress, Amyloid-Beta, and Tau Pathology in vitro. Mol. Pharm. 2019, 16, 1456-1466. [CrossRef] [PubMed]

173. Raghava Rao, K.V.; Mani, P.; Satyanarayana, B.; Raghava Rao, T. Purification and structural elucidation of three bioactive compounds isolated from Streptomyces coelicoflavus BC 01 and their biological activity. 3 Biotech 2017, 7. [CrossRef] [PubMed]

174. Bae, M.; Park, S.H.; Kwon, Y.; Lee, S.K.; Shin, J.; Nam, J.W.; Oh, D.C. QM-HiFSA-aided structure determination of succinilenes A-D, new triene polyols from a marine-derived Streptomyces sp. Mar. Drugs 2017, 15, 38. [CrossRef] [PubMed]

175. Hassan, H.M.; Boonlarppradab, C.; Fenical, W. Actinoquinolines A and B, anti-inflammatory quinoline alkaloids from a marine-derived Streptomyces sp., strain CNP975. J. Antibiot. 2016, 69, 511-514. [CrossRef]

176. Lee, J.; Kim, H.; Lee, T.G.; Yang, I.; Won, D.H.; Choi, H.; Nam, S.J.; Kang, H. Anmindenols A and B, inducible nitric oxide synthase inhibitors from a marine-derived Streptomyces sp. J. Nat. Prod. 2014, 77, 1528-1531. [CrossRef]

177. Lee, D.S.; Yoon, C.S.; Jung, Y.T.; Yoon, J.H.; Kim, Y.C.; Oh, H. Marine-Derived Secondary Metabolite, Griseusrazin A, Suppresses Inflammation through Heme Oxygenase-1 Induction in Activated RAW264.7 Macrophages. J. Nat. Prod. 2016, 79, 1105-1111. [CrossRef] [PubMed]

178. Li, H.; Huang, H.; Hou, L.; Ju, J.; Li, W. Discovery of antimycin-type depsipeptides from a wbl gene mutant strain of deepsea-derived Streptomyces somaliensis SCSIO ZH66 and their effects on pro-inflammatory cytokine production. Front. Microbiol. 2017, 8, 1-8. [CrossRef] [PubMed]

179. Strangman, W.K.; Kwon, H.C.; Broide, D.; Jensen, P.R.; Fenical, W. Potent inhibitors of pro-inflammatory cytokine production produced by a marine-derived bacterium. J. Med. Chem. 2009, 52, 2317-2327. [CrossRef]

180. Yang, X.W.; Peng, K.; Liu, Z.; Zhang, G.Y.; Li, J.; Wang, N.; Steinmetz, A.; Liu, Y. Strepsesquitriol, a rearranged zizaane-type sesquiterpenoid from the deep-sea-derived actinomycete Streptomyces sp. SCSIO 10355. J. Nat. Prod. 2013, 76, 2360-2363. [CrossRef] [PubMed]

181. Park, E.J.; Pezzuto, J.M.; Jang, K.H.; Nam, S.J.; Bucarey, S.A.; Fenical, W. Suppression of nitric oxide synthase by thienodolin in lipopolysaccharide- stimulated RAW 264.7 murine macrophage cells. Nat. Prod. Commun. 2012, 7, 789-794. [CrossRef] [PubMed] 
182. Renner, M.K.; Shen, Y.C.; Cheng, X.C.; Jensen, P.R.; Frankmoelle, W.; Kauffman, C.A.; Fenical, W.; Lobkovsky, E.; Clardy, J. Cyclomarins A-C, new antiinflammatory cyclic peptides produced by a marine bacterium (Streptomyces sp.). J. Am. Chem. Soc. 1999, 121, 11273-11276. [CrossRef]

183. Cheng, C.; Othman, E.M.; Reimer, A.; Grüne, M.; Kozjak-Pavlovic, V.; Stopper, H.; Hentschel, U.; Abdelmohsen, U.R. Ageloline A, new antioxidant and antichlamydial quinolone from the marine sponge-derived bacterium Streptomyces sp. SBT345. Tetrahedron Lett. 2016, 57, 2786-2789. [CrossRef]

184. Wen, L.; Chen, G.; Zhang, S.; You, T.; Liu, F.; Fu, Y.; Yao, X. In vitro antioxidant and acetylcholinesterase inhibitory activities of the sesquiterpenes of a symbiotic actinomycete Streptomyces sp. from South China sea. Asian J. Chem. 2013, 25, 6865-6869. [CrossRef]

185. Ramalingam, V.; Rajaram, R. Antioxidant activity of 1-hydroxy-1-norresistomycin derived from Streptomyces variabilis KP149559 and evaluation of its toxicity against zebra fish Danio rerio. RSC Adv. 2016, 6, 16615-16623. [CrossRef]

186. Ai, W.; Lin, X.P.; Tu, Z.; Tian, X.P.; Lu, X.; Mangaladoss, F.; Zhong, Z.L.; Liu, Y. Axinelline A, a new COX-2 inhibitor from Streptomyces axinellae SCSIO02208. Nat. Prod. Res. 2014, 28, 1219-1224. [CrossRef]

187. Ali, A.; Khajuria, A.; Sidiq, T.; Kumar, A.; Thakur, N.L.; Naik, D.; Vishwakarma, R.A. Modulation of LPS induced inflammatory response by Lawsonyl monocyclic terpene from the marine derived Streptomyces sp. Immunol. Lett. 2013, 150, 79-86. [CrossRef] [PubMed]

188. Lee, H.S.; An, B.J.; Kim, H.J.; Cho, Y.H.; Kim, D.I.; Jang, J.Y.; Kwak, J.H.; Lee, H.S.; Lee, Y.J.; Lee, J.S.; et al. Anti-inflammatory effect of violapyrones B and C from a marine-derived Streptomyces sp. Nat. Prod. Sci. 2015, 21, 251-254. [CrossRef]

189. Nalli, Y.; Gupta, S.; Khajuria, V.; Singh, V.P.; Sajgotra, M.; Ahmed, Z.; Thakur, N.L.; Ali, A. TNF- $\alpha$ and IL-6 inhibitory effects of cyclic dipeptides isolated from marine bacteria Streptomyces sp. Med. Chem. Res. 2017, 26, 93-100. [CrossRef]

190. Trischman, J.A.; Tapiolas, D.M.; Jensen, P.R.; Dwight, R.; Fenical, W.; McKee, T.C.; Ireland, C.M.; Stout, T.J.; Clardy, J. Salinamides A and B: Anti-inflammatory depsipeptides from a marine streptomycete. J. Am. Chem. Soc. 1994, 116, 757-758. [CrossRef]

191. Leirós, M.; Alonso, E.; Sanchez, J.A.; Rateb, M.E.; Ebel, R.; Houssen, W.E.; Jaspars, M.; Alfonso, A.; Botana, L.M. Mitigation of ROS insults by streptomyces secondary metabolites in primary cortical neurons. ACS Chem. Neurosci. 2014, 5, 71-80. [CrossRef] [PubMed]

192. Kim, K.-Y.; Lee, S.-G.; Baek, S.Y.; Lee, E.H.; Jang, E.J.; Lee, J.-H.; Ahn, S.-C.; Chang, J.-H.; Oh, T.W.; Kim, S.-H.; et al. Salinomycin ameliorates oxidative hepatic damage through AMP-activated protein kinase, facilitating autophagy. Toxicol. Appl. Pharmacol. 2018, 360, 141-149. [CrossRef]

193. Shin-ya, K.; Furihata, K.; Teshima, Y.; Hayakawa, Y.; Seto, H. Structures of stealthins A and B, new free radical scavengers of microbial origin. Tetrahedron Lett. 1992, 33, 7025-7028. [CrossRef]

194. Shin-ya, K.; Tanaka, M.; Furihata, K.; Hayakawa, Y.; Seto, H. Structure of carquinostatin a, a new neuronal cell protecting substance produced by Streptomyces exfoliatus. Tetrahedron Lett. 1993, 34, 4943-4944. [CrossRef]

195. Takagi, H.; Motohashi, K.; Miyamoto, T.; Shin-ya, K.; Furihata, K.; Seto, H. Studies on terpenoids produced by actinomycetes isolation and structural elucidation of antioxidative agents, naphterpins B and C. J. Antibiot. 2005, 58, 275-278. [CrossRef]

196. Shin-Ya, K.; Imai, S.; Furihata, K.; Hayakawa, Y.; Kato, Y.; Vanduyne, G.D.; Clardy, J.; Seto, H. Isolation and structural elucidation of an antioxidative agent, naphterpin. J. Antibiot. 1990, 43, 444-447. [CrossRef]

197. Komoda, T.; Tamiya, Y.; Nishikawa, M. 10T024A, a New phenazine derivative, as a radical scavenger and a prostaglandin, leukotriene release suppressor. Biosci. Biotechnol. Biochem. 2011, 75, 2056-2058. [CrossRef] [PubMed]

198. Takeiri, M.; Ota, E.; Nishiyama, S.; Kiyota, H.; Umezawa, K. Structure-activity relationship of 9-methylstreptimidone, a compound that induces apoptosis selectively in adult T-cell leukemia cells. Oncol. Res. 2012, 20,7-14. [CrossRef] [PubMed]

199. Ding, R.; Tang, J.; Gao, H.; Li, T.; Zhou, H.; Liu, L.; Yao, X.S. New methymycin derivatives of Streptomyces venezuelae ATCC 15439 and their inhibitory effects on human T cell proliferation mediated by PMA/ionomycin. Arch. Pharm. Res. 2012, 35, 1567-1572. [CrossRef] [PubMed]

200. Kuriyama, K.; Fujiwara, A.; Inagaki, K.; Abe, Y. Anti-inflammatory action of a novel peptide, SEK-1005, isolated from a Streptomyces. Eur. J. Pharmacol. 2000, 390, 223-228. [CrossRef] 
201. Mori, A.; Kaminuma, O.; Ogawa, K.; Nakata, A.; Egan, R.W.; Akiyama, K.; Okudaira, H. Control of IL-5 production by human helper $\mathrm{T}$ cells as a treatment for eosinophilic inflammation: Comparison of in vitro and in vivo effects between selective and nonselective cytokine synthesis inhibitors. J. Allergy Clin. Immunol. 2000, 106, S58-S64. [CrossRef]

202. Kondratyuk, T.P.; Park, E.J.; Yu, R.; Van Breemen, R.B.; Asolkar, R.N.; Murphy, B.T.; Fenical, W.; Pezzuto, J.M. Novel marine phenazines as potential cancer chemopreventive and anti-inflammatory agents. Mar. Drugs 2012, 10, 451-464. [CrossRef] [PubMed]

203. Sander, T.; Freyss, J.; Von Korff, M.; Rufener, C. DataWarrior: An open-source program for chemistry aware data visualization and analysis. J. Chem. Inf. Model. 2015, 55, 460-473. [CrossRef] [PubMed]

204. Gibbs, A.C.; Agrafiotis, D.K. Chemical diversity: Definition and quantification. In Exploiting Chemical Diversity for Drug Discovery; Bartlett, P.A., Entzeroth, M., Eds.; RSC Publishing: Cambridge, UK, 2006; pp. 136-159.

205. Salomon, C.E.; Magarvey, N.A.; Sherman, D.H. Merging the potential of microbial genetics with biological and chemical diversity: An even brighter future for marine natural product drug discovery. Nat. Prod. Rep. 2004, 21, 105. [CrossRef]

206. Aniszewski, T. Evolution of alkaloids and alkaloids in evolution. In Alkaloids; Elsevier: Amsterdam, The Netherlands, 2015; pp. 291-344.

207. Couteau, C.; Chauvet, C.; Paparis, E.; Coiffard, L. UV Filters, Ingredients with a Recognized Anti-Inflammatory Effect. PLoS ONE 2012, 7, 2-7. [CrossRef]

208. Sayre, R.M.; Dowdy, J.C.; Rosenberg, E.W. Sun-protection factor confounded by anti-inflammatory activity of sunscreen agents? J. Am. Acad. Dermatol. 2013, 69, 481. [CrossRef]

209. Lecumberri Lima, E.; Calderón Muñoz, L.; Expósito Harris, R.; Heras Caballero, Á.M. Potential applications of chitosan as a marine cosmeceutical. In Marine Cosmeceuticals: Trends and Prospects; Kim, S.-K., Ed.; CRC Press: Boca Raton, FL, USA, 2011; pp. 319-333.

210. Von Korff, M.; Sander, T. Toxicity-indicating structural patterns. J. Chem. Inf. Model. 2006, 46, 536-544. [CrossRef] [PubMed]

211. Khan, T.; Ahmad, R.; Azad, I.; Raza, S.; Joshi, S.; Khan, A.R. Computer-aided drug design and virtual screening of targeted combinatorial libraries of mixed-ligand transition metal complexes of 2-butanone thiosemicarbazone. Comput. Biol. Chem. 2018, 75, 178-195. [CrossRef] [PubMed]

212. Moloney, F.J.; Collins, S.; Murphy, G.M. Sunscreens: Safety, efficacy and appropriate use. Am. J. Clin. Dermatol. 2002, 3, 185-191. [CrossRef] [PubMed]

213. Hu, Y.; Stumpfe, D.; Bajorath, J. Advancing the activity cliff concept. F1000Research 2013, 2, 199. [CrossRef] [PubMed]

214. Özakin, S.; Davis, R.W.; Umile, T.P.; Pirinccioglu, N.; Kizil, M.; Celik, G.; Sen, A.; Minbiole, K.P.C.; İnce, E. The isolation of tetrangomycin from terrestrial Streptomyces sp. CAH29: Evaluation of antioxidant, anticancer, and anti-MRSA activity. Med. Chem. Res. 2016, 25, 2872-2881. [CrossRef]

215. Guha, R.; Van Drie, J.H. Structure-Activity landscape index: Identifying and quantifying activity cliffs. J. Chem. Inf. Model. 2008, 48, 646-658. [CrossRef]

216. Galano, A.; Mazzone, G.; Alvarez-Diduk, R.; Marino, T.; Alvarez-Idaboy, J.R.; Russo, N. Food Antioxidants: Chemical Insights at the Molecular Level. Annu. Rev. Food Sci. Technol. 2016, 7, 335-352. [CrossRef]

217. Apak, R.; Özyürek, M.; Güçlü, K.; Çapanoğlu, E. Antioxidant activity/capacity measurement. 1. Classification, physicochemical principles, mechanisms, and electron transfer (ET)-based assays. J. Agric. Food Chem. 2016, 64, 997-1027. [CrossRef]

218. Kemung, H.M.; Tan, L.T.H.; Khan, T.M.; Chan, K.G.; Pusparajah, P.; Goh, B.H.; Lee, L.H. Streptomyces as a prominent resource of future anti-MRSA drugs. Front. Microbiol. 2018, 9, 1-26. [CrossRef]

219. Hassan, Q.P.; Bhat, A.M.; Shah, A.M. Bioprospecting Actinobacteria for Bioactive Secondary Metabolites From Untapped Ecoregions of the Northwestern Himalayas. In New and Future Developments in Microbial Biotechnology and Bioengineering; Elsevier: Amsterdam, The Netherlands, 2019; pp. 77-85. ISBN 9780444635044.

220. Vicente, C.M.; Thibessard, A.; Lorenzi, J.N.; Benhadj, M.; Hôtel, L.; Gacemi-Kirane, D.; Lespinet, O.; Leblond, P.; Aigle, B. Comparative genomics among closely related streptomyces strains revealed specialized metabolite biosynthetic gene cluster diversity. Antibiotics 2018, 7, 86. [CrossRef]

221. Seipke, R.F. Strain-level diversity of secondary metabolism in Streptomyces albus. PLoS ONE 2015, 10, 1-14. [CrossRef] [PubMed] 
222. O'Brien, J.; Wright, G.D. An ecological perspective of microbial secondary metabolism. Curr. Opin. Biotechnol. 2011, 22, 552-558. [CrossRef] [PubMed]

223. O'Brien, P.; Carrasco-Pozo, C.; Speisky, H. Boldine and its antioxidant or health-promoting properties. Chem. Biol. Interact. 2006, 159, 1-17. [CrossRef] [PubMed]

224. Fan, H.; Peng, J.; Hamann, M.T.; Hu, J.-F. Lamellarins and Related Pyrrole-Derived Alkaloids from Marine Organisms. Chem. Rev. 2008, 108, 264-287. [CrossRef] [PubMed]

225. Gill, S.S.; Tuteja, N. Reactive oxygen species and antioxidant machinery in abiotic stress tolerance in crop plants. Plant Physiol. Biochem. 2010, 48, 909-930. [CrossRef] [PubMed]

226. Baltina, L. Chemical Modification of Glycyrrhizic Acid as a Route to New Bioactive Compounds for Medicine. Curr. Med. Chem. 2003, 10, 155-171. [CrossRef] [PubMed]

227. Banoglu, E.; Akoğlu, Ç.; ünlü, S.; Küpeli, E.; Yeşilada, E.; Şahin, M.F. Amide Derivatives of [6-(5-Methyl-3-phenylpyrazole-1-yl)-3(2H)-pyridazinone-2-yl]acetic Acids as Potential Analgesic and Anti-Inflammatory Compounds. Arch. Pharm. 2004, 337, 7-14. [CrossRef] [PubMed]

228. Re, G.; Barbero, R.; Miolo, A.; Di Marzo, V. Palmitoylethanolamide, endocannabinoids and related cannabimimetic compounds in protection against tissue inflammation and pain: Potential use in companion animals. Vet. J. 2007, 173, 21-30. [CrossRef]

229. Lee, Y.-T.; Hsieh, Y.-L.; Yeh, Y.-H.; Huang, C.-Y. Synthesis of phenolic amides and evaluation of their antioxidant and anti-inflammatory activity in vitro and in vivo. RSC Adv. 2015, 5, 85806-85815. [CrossRef]

230. Hellberg, M.R.; Namil, A.; Delgado, P.; David, K.C.; Kessler, T.L.; Graff, G.; Haggard, K.S.; Nixon, J.C. Novel Esters and Amides of Nonsteroidal Antiinflammatory Carboxylic Acids as Antioxidants and Antiproliferative Agents. J. Med. Chem. 1999, 42, 267-276. [CrossRef]

231. Braun-Falco, O.; Plewig, G.; Wolff, H.H.; Winkelmann, R.K. Dermatology; Springer: Berlin/Heidelberg, Germany, 1991; ISBN 978-3-662-00183-7.

232. Hwang, K.S.; Kim, H.U.; Charusanti, P.; Palsson, B.T.; Lee, S.Y. Systems biology and biotechnology of Streptomyces species for the production of secondary metabolites. Biotechnol. Adv. 2014, 32, 255-268. [CrossRef] [PubMed]

233. Weber, T.; Charusanti, P.; Musiol-Kroll, E.M.; Jiang, X.; Tong, Y.; Kim, H.U.; Lee, S.Y. Metabolic engineering of antibiotic factories: New tools for antibiotic production in actinomycetes. Trends Biotechnol. 2015, 33, 15-26. [CrossRef] [PubMed]

234. Nieselt, K.; Battke, F.; Herbig, A.; Bruheim, P.; Wentzel, A.; Jakobsen, Ø.M.; Sletta, H.; Alam, M.T.; Merlo, M.E.; Moore, J.; et al. The dynamic architecture of the metabolic switch in Streptomyces coelicolor. BMC Genom. 2010, 11, 10. [CrossRef] [PubMed]

235. Liu, G.; Chater, K.F.; Chandra, G.; Niu, G.; Tan, H. Molecular Regulation of Antibiotic Biosynthesis in Streptomyces. Microbiol. Mol. Biol. Rev. 2013, 77, 112-143. [CrossRef] [PubMed]

236. Luo, Y.; Huang, H.; Liang, J.; Wang, M.; Lu, L.; Shao, Z.; Cobb, R.E.; Zhao, H. Activation and characterization of a cryptic polycyclic tetramate macrolactam biosynthetic gene cluster. Nat. Commun. 2013, 4, 2894. [CrossRef]

237. Bai, C.; Zhang, Y.; Zhao, X.; Hu, Y.; Xiang, S.; Miao, J.; Lou, C.; Zhang, L. Exploiting a precise design of universal synthetic modular regulatory elements to unlock the microbial natural products in Streptomyces. Proc. Natl. Acad. Sci. USA 2015, 112, 12181-12186. [CrossRef]

238. Apak, R.; Gorinstein, S.; Böhm, V.; Schaich, K.M.; Özyürek, M.; Güçlü, K. Methods of measurement and evaluation of natural antioxidant capacity/activity (IUPAC Technical Report). Pure Appl. Chem. 2013, 85, 957-998. [CrossRef]

239. Sharma, O.P.; Bhat, T.K. DPPH antioxidant assay revisited. Food Chem. 2009, 113, 1202-1205. [CrossRef]

240. Perricone, N.V.; DiNardo, J.C. Photoprotective and Antiinflammatory Effects of Topical Glycolic Acid. Dermatol. Surg. 1996, 22, 435-437. [CrossRef]

241. Edlich, R.F.; Winters, K.L.; Lim, H.W.; Cox, M.J.; Becker, D.G.; Horowitz, J.H.; Nichter, L.S.; Britt, L.D.; Long, W.B. Photoprotection by Sunscreens with Topical Antioxidants and Systemic Antioxidants to Reduce Sun Exposure. J. Long. Term. Eff. Med. Implants 2004, 14, 317-340. [CrossRef] 
242. Matsui, M.S.; Hsia, A.; Miller, J.D.; Hanneman, K.; Scull, H.; Cooper, K.D.; Baron, E. Non-Sunscreen Photoprotection: Antioxidants Add Value to a Sunscreen. J. Investig. Dermatol. Symp. Proc. 2009, 14, 56-59. [CrossRef] [PubMed]

243. Stevanato, R.; Bertelle, M.; Fabris, S. Photoprotective characteristics of natural antioxidant polyphenols. Regul. Toxicol. Pharmacol. 2014, 69, 71-77. [CrossRef] [PubMed] 